\title{
$\gamma$-Actin plays a key role in endothelial cell motility and neovessel maintenance
}

\author{
Vascular Cell 7:2 | DOI: 10.1186/s13221-014-0027-2 I C Li et al.; licensee Publiverse Online S.R.L. \\ 2015 \\ Received: 17 Sep 2014 I Accepted: 29 Sep 2014 I Published: 6 Sep 2015 \\ Pasquier Eddy, Tuset Maria-Pia, Sinnappan Snega, Carnell Michael, Macmillan Alexander, \\ Kavallaris Maria@ \\ ${ }^{+}$Contributed equally ${ }^{@}$ Corresponding author
}

\section{Abstract}

\section{Background}

Angiogenesis plays a crucial role in development, wound healing as well as tumour growth and metastasis. Although the general implication of the cytoskeleton in angiogenesis has been partially unravelled, little is known about the specific role of actin isoforms in this process. Herein, we aimed at deciphering the function of $\gamma$-actin in angiogenesis.

\section{Methods}

Localization of $\beta$ - and $\gamma$-actin in vascular endothelial cells was investigated by co-immunofluorescence staining using monoclonal antibodies, followed by the functional analysis of $\gamma$-actin using siRNA. The impact of $\gamma$-actin knockdown on the random motility and morphological differentiation of endothelial cells into vascular networks was investigated by timelapse videomicroscopy while the effect on chemotaxis was assessed using modified Boyden chambers. The implication of VE-cadherin, VEGFR-2 and ROCK signalling was then examined by Western blotting and using pharmacological inhibitors.

\section{Results}

The two main cytoplasmic isoforms of actin strongly co-localized in vascular endothelial cells, albeit with some degree of spatial preference. While $\beta$-actin knockdown was not achievable without major cytotoxicity, $\gamma$-actin knockdown did not alter the viability of endothelial cells. Timelapse videomicroscopy experiments revealed that $\gamma$-actin knockdown cells were able to initiate morphological differentiation into capillary-like tubes but were unable to maintain these structures, which rapidly regressed. This vascular regression was associated with altered regulation of VE-cadherin expression. Interestingly, knocking down $\gamma$-actin expression had no effect on endothelial cell adhesion to various substrates but significantly decreased their motility and migration. This anti-migratory effect was associated with an accumulation of thick actin stress fibres, large focal adhesions and increased phosphorylation of myosin regulatory light chain, suggesting activation of the ROCK signalling pathway. Incubation with ROCK inhibitors, H-1152 and Y-27632, completely rescued the motility phenotype induced by $\gamma$-actin knockdown but only partially restored the angiogenic potential of endothelial cells.

\section{Conclusions}

Our study thus demonstrates for the first time that $\beta$-actin is essential for endothelial cell survival and $\gamma$ actin plays a crucial role in angiogenesis, through both ROCK-dependent and -independent mechanisms. 
This provides new insights into the role of the actin cytoskeleton in angiogenesis and may open new therapeutic avenues for the treatment of angiogenesis-related disorders.

\section{Keywords}

Cytoskeleton - Actin - Angiogenesis - Vascular endothelial cells - ROCK signalling

\section{Background}

Angiogenesis is defined as the formation of new blood vessels from pre-existing ones. It is crucial for organ growth during development but also throughout adult life to repair wounded tissues. Furthermore, an imbalance in this process directly contributes to numerous pathologies such as cancer, diabetes, agerelated macular degeneration, ischemic disorders and rheumatoid arthritis [ 1,2]. The multi-step and complex process leading to the formation of a new vascular network relies on the activation of endothelial cells followed by their proliferation, migration and morphological differentiation into capillary tubes. The cytoskeleton which directly regulates and controls an impressive array of cell functions, including cell shape maintenance, cell division, vesicle and organelle transport, cell motility and differentiation, plays a major role in angiogenesis. Studies focusing on the anti-angiogenic properties of microtubule-targeting drugs - reviewed by Pasquier et al. [ 3] - have provided major insights into the role of microtubules in this process. However, very little is known about the specific role of actin isoforms in angiogenesis.

In vertebrates, there are 6 functional actin genes and the expression of the six actin isoforms is regulated both spatially and temporally in a tissue-specific manner. Four of these isoforms (i.e. $\alpha$-cardiac muscle actin, $\alpha$-skeletal muscle actin, $\alpha$-smooth muscle actin and $\gamma$-smooth muscle actin) are mainly expressed in muscle cells, while the cytoplasmic isoforms $\beta$ - and $\gamma$-actin are ubiquitous [4]. Interestingly, the $\beta$ and $\gamma$-actin isoforms are almost identical proteins, differing only by 4 amino acid residues at the $\mathrm{N}$ terminal end (positions 1,2,3 and 9). Distinct localization of $\beta$ - and $\gamma$-actin mRNAs in several cell types, such as neurons, myoblasts and osteoblasts, has suggested for almost 20 years a spatial segregation of the two isoforms [ 5,6]. However, the spatial and functional segregation of $\beta$ - and $\gamma$-actin was confirmed only recently in fibroblasts and epithelial cells by Chaponnier and colleagues, using newly developed monoclonal antibodies [ 7]. In particular, $\beta$-actin appears to play a role in cell attachment and contraction by preferentially localizing to stress fibres whereas $\gamma$-actin is mainly organised as a meshwork in cortical and lamellipodial structures and thus plays a crucial role in cell motility [7]. In accordance with this finding, we recently demonstrated that $\gamma$-actin specifically regulates cell motility by modulating the Rho-associated kinase (ROCK) signalling pathway and therefore influencing the phosphorylation of focal adhesion protein paxillin and myosin regulatory light chain 2 in neuroblastoma cells [ 8]. Elsewhere, key functional differences between $\beta$ - and $\gamma$-actin were also recently revealed by mouse knock-out experiments. Indeed, $\beta$-actin knock-out mice are not viable, in part due to severe growth and migration defects of $\beta$-actin null embryonic cells, which are not observed in $\gamma$-actin null embryonic cells [9]. In contrast, $\gamma$-actin knock-out mice are viable, despite suffering increased mortality at birth and progressive hearing loss, which suggests that $\gamma$-actin is required for cytoskeleton maintenance but not for development [10]. Spatial segregation and functional differences led us to hypothesize that $\beta$ - and $\gamma$-actin may play distinct roles in endothelial cells and differentially contribute to angiogenesis. We therefore investigated the localization of $\beta$ - and $\gamma$-actin in vascular endothelial cells and undertook the functional analysis of $\gamma$-actin by RNAi to decipher its specific function in endothelial cell adhesion, motility and morphological differentiation into vascular networks, thus revealing a key role in angiogenesis.

\section{Material and methods}

\section{Cell culture}

HMEC-1 endothelial cells were originally isolated from dermal microvessels and immortalized by transfection with SV40 large T antigen [11]. They were obtained from the Cell Culture Laboratory in the Hôpital de la Conception (Assistance Publique Hôpitaux de Marseille, Marseille, France) and grown in MCDB-131 medium (Invitrogen, Mount Waverley, Australia) containing 10\% heat-inactivated Fetal 
Calf Serum (FCS), $2 \mathrm{mM} \mathrm{L-glutamine,} 1 \%$ penicillin and streptomycin, $1 \mu \mathrm{g} / \mathrm{mL}$ hydrocortisone and $10 \mathrm{ng} / \mathrm{mL}$ epithelial growth factor (BioScientific, Gymea, Australia). BMH29L cells are bone marrow derived endothelial cells that were immortalized by ectopic expression of human telomerase reverse transcriptase [ 12]. They were kindly provided by Dr Karen MacKenzie (Children's Cancer Institute Australia) and grown in Medium 199 (Invitrogen) containing 10\% heat-inactivated FCS, 5\% male human serum AB only (Sigma-Aldrich, Castle Hill, Australia), 1\% penicillin and streptomycin, $1 \%$ heparin, $5 \mathrm{ng} / \mathrm{mL}$ recombinant human FGF $\beta$ (fibroblast growth factor $\beta$; Sigma-Aldrich) and $20 \mu \mathrm{g} / \mathrm{mL}$ Endothelial Cell Growth Factor (ECGF; Roche, Dee Why, Australia). Both cell lines were routinely maintained in culture on $0.1 \%$ gelatin-coated flasks at $37^{\circ} \mathrm{C}$ and $5 \% \mathrm{CO}{ }_{2}$. Cell lines were regularly screened and are free from mycoplasma contamination.

\section{Gene silencing}

$\gamma$-actin gene expression was silenced in endothelial cells using the siRNA sequence previously described (5'-AAGAGATCGCCGCGCTGGTCA-3'; Qiagen, Doncaster, Australia) [ 13]. An alternative siRNA sequence (5'-CAGCAACACGTCATTGTGTAA-3'; Qiagen) was also used in confirmation experiments [ 8]. $\beta$-actin gene expression was targeted using the siRNA sequence previously described $\left(5^{\prime}\right.$ -

AATGAAGATCAAGATCATTGC-3'; Qiagen) [ 14]. The optimum amount of siRNA was determined to be 200 and 500 pmol for HMEC-1 and BMH29L cells, respectively and was used in all subsequent experiments. A non-silencing control siRNA, which has no sequence homology to any known human gene sequence, was used as a negative control in all experiments (Qiagen). Cells were transfected using the Nucleofector ${ }^{\circledR}$ II device (Lonza, Mount Waverley, Australia) as previously described [ 15]. Briefly, HMEC-1 and BMH29L cells were resuspended in nucleofector ${ }^{\circledR}$ solution R and V, respectively, and transfected with siRNA using specifically optmized nucleofector ${ }^{\circledR}$ programs (T-016 and S-003 for HMEC-1 and BMH29L, respectively). All subsequent experiments were performed $72 \mathrm{~h}$ after siRNA transfection, when the level of $\gamma$-actin protein expression was the lowest.

\section{Quantitative RT-PCR}

The expression of $\gamma$-actin mRNA was examined using quantitative RT-PCR. Total RNA was extracted and DNase treated using the Qiagen RNeasy Plus kit according to the manufacturer's instructions (Qiagen) and cDNA synthesis was performed using High capacity cDNA reverse transcription kit with RNAse inhibitor (Applied Biosystems, Mulgrave, Australia). Real-time PCR was performed on 7900HT Fast Real-time PCR system using the TaqMan ${ }^{\circledR}$ gene expression Master Mix (Applied Biosystems). $\gamma$ actin mRNA primer and probe sequences used were as follows: forward, $5^{\prime}-$ CAGCTCTCGCACTCTGTTCTTC-3'; reverse, 5'-ACATGCCGGAGCCATTGT-3'; probe, 5'CGCGCTGGTCATT-3' . All data were normalized to the housekeeping gene Ppia (peptidilprolyl isomerase A, TaqMan ${ }^{\circledR}$ Endogenous Control, Applied Biosystems). Gene expression levels were determined using the $\Delta \Delta C$ tmethod, normalized to the housekeeper gene and expressed relative to a calibrator [ 16].

\section{Western blotting analysis}

For western blotting analysis, cells were lysed in RIPA buffer containing a cocktail of protease and phosphatase inhibitors (Sigma-Aldrich). Equal amounts of protein $(10-15 \mu \mathrm{g})$ were resolved on $12 \%$ sodium dodecyl sulfate polyacrylamide gel electrophoresis or 4-15\% pre-cast Criterion acrylamide gels (Bio-Rad Laboratories, Gladesville, Australia) before electrotransfer onto nitrocellulose membrane. Immunoblotting was performed using antibodies directed against $\beta$-actin (clone AC-74, Sigma-Aldrich), $\gamma$-actin - courtesy of Pr Peter Gunning [ 17], GAPDH (Abcam, Cambridge, UK), phospho-myosin light chain 2 (Cell Signaling Technology, Beverly, MA, USA), VE-cadherin (Cell signaling technology) and VEGFR-2 (Cell signaling technology). The membranes were then incubated with horseradish peroxidase-conjugated IgG secondary antibodies and protein detected with ECL Plus (GE Healthcare Life Sciences, Uppsala, Sweden). The blots were scanned and densitometric analysis performed as previously described [ 13].

\section{Immunofluorescence staining}

Vascular endothelial cells were seeded on gelatin-coated 8-well Permanox Lab-Tek chamber slides (Applied Biosystems) after siRNA transfection. $\beta$-actin and $\gamma$-actin were stained as previously described [ 7] with slight modifications. Specifically, cells were fixed with $3.7 \%$ formaldehyde for $20 \mathrm{~min}$ at RT 
and permeabilized with $100 \%$ methanol for $20 \mathrm{~min}$ at $-20^{\circ} \mathrm{C}$. Cells were incubated with the following primary mAbs: anti- $\beta$-actin (mAb 4C2, IgG1 - courtesy of Pr Christine Chaponnier [ 7]) and anti- $\gamma$ actin (mAb 2A3, IgG2b - courtesy of Pr Christine Chaponnier [ 7]). The following secondary Abs were used: FITC-conjugated goat anti-mouse IgG1 (Southern Biotechnology, Birmingham, AL) and TRITCconjugated goat anti-mouse IgG2b (Southern Biotechnology). For tubulin staining, cells were fixed and permeabilized in $100 \%$ methanol at $20^{\circ} \mathrm{C}$ for 15 min and blocked with $10 \%$ FCS for 30 min.

Microtubules were then stained with anti- $\beta$ I-tubulin primary antibody (Abcam), followed by Alexa Fluor 488 anti-mouse secondary antibody (Invitrogen). For paxillin and phalloidin dual staining, cells were fixed with $3.7 \%$ formaldehyde/PBS for $10 \mathrm{~min}$ and permeabilized with $0.1 \%$ Triton X-100/PBS for $5 \mathrm{~min}$. Focal adhesions were then stained with anti-paxillin primary antibody (BD Biosciences), followed by Alexa Fluor 488 anti-mouse secondary antibody (Invitrogen) and Alexa 568-conjugated phalloidin (Invitrogen). All slides were mounted on coverslips with ProLong Gold anti-fade reagent containing DAPI (Invitrogen) and imaged using the 63X oil-immersion objective of an Axiovert $200 \mathrm{M}$ fluorescent microscope coupled to an AxioCamMR3 camera driven by the AxioVision 4.8 software (Carl Zeiss, North Ryde, Australia). The thickness of actin stress fibres was determined performing a line scan perpendicular to the fibres using Image $J$, while the size of paxillin-containing adhesion sites was measured using the AxioVision 4.8 software.

\section{Colocalization analysis}

Colocalization between $\beta$-actin and $\gamma$-actin channels was assessed by measuring the Pearson's Correlation Coefficient and visually inspecting two-dimensional histograms (fluorograms). The Pearson's coefficient measures the linear relationship between the pixel intensities of two channels. In the case of positive correlation this value can drop either due to decreasing colocalization, or due to differences in stoichiometry in structures. The fluorogram can distinguish these two scenarios, low colocalization shows by dispersion of points whilst varying stochiometries show multiple tight linear clusters. Measurements were made using the Coloc 2 plugin in ImageJ (imagej.nih.gov/ij). Image background was carefully subtracted from each channel and regions of interest were drawn around each cell to exclude extracellular pixels from the measurement. Measurements were performed on single cells to ensure variations in expression and staining did not contribute to multiple stoichiometries.

\section{Adhesion assay}

For the adhesion assay, cells were pre-labeled in situ with $10 \mu \mathrm{M}$ Cell Tracker Green CMFDA (Invitrogen) in serum-free medium for $30 \mathrm{~min}$ and 50,000 cells were then seeded onto 24-well plates, pre-coated for 2 hours at $37^{\circ} \mathrm{C}$ with various extra-cellular matrix (ECM) proteins: fibronectin $(2 \mu \mathrm{g} / \mathrm{mL})$, laminin $(10 \mu \mathrm{g} / \mathrm{mL})$ or type I collagen $(10 \mu \mathrm{g} / \mathrm{mL})$. After 1 hour incubation, cells were washed twice with PBS and the number of adhered cells was assessed with a Victor 3 plate reader (Perkin-Elmer, Glen Waverley, Australia) at 492/517 (Abs/Em). All readings were then normalized to the negative control (no ECM).

\section{Chemotaxis assay}

The chemotaxis assay was performed as previously described [ 18]. Briefly, the underside of $8 \mu \mathrm{m}$ transparent polyethylene terephthalate membrane inserts (BD Falcon) was pre-coated with $0.1 \%$ gelatin for $1 \mathrm{~h}$. The cells were pre-labeled in situ with $10 \mu \mathrm{M}$ Cell Tracker Green CMFDA (Invitrogen) in serum-free medium for $30 \mathrm{~min}$ and 100,000 cells were then seeded onto the insert in assay medium (0.5\% BSA in serum-free medium). Assay medium supplemented with $5 \% \mathrm{FCS}, 0.1 \mathrm{ng} / \mathrm{mL}$ VEGF-A, $5 \mathrm{ng} / \mathrm{mL} \mathrm{FGF}{ }_{\beta}$ or $20 \mu \mathrm{g} / \mathrm{mL}$ ECGF was then added to the bottom of the insert and used as chemoattractant. A negative control was included in each experiment by adding serum-free medium to the bottom of the insert. The plates were incubated for $6 \mathrm{~h}$ at $37^{\circ} \mathrm{C}$ and $5 \% \mathrm{CO}{ }_{2}$. Excess cells on the upper side of the insert were then gently swabbed off with a cotton tip and migrated cells at the underside of the insert were measured with the same plate reader used for the adhesion assay. All readings were then normalized to the negative control (serum-free medium).

\section{Random motility assay}

Random cell motility was assessed by time-lapse microscopy as previously described [ 18]. Briefly, cells were seeded on a 24-well gelatin-coated plate and allowed to adhere for $1 \mathrm{~h}$. Photographs were then taken every $5 \mathrm{~min}$ for $6 \mathrm{~h}$ in at least 2 view fields per well using the $5 \mathrm{X}$ objective of the same 
microscope device used for immunofluorescence experiments. During this assay, cells were constantly maintained at $37^{\circ} \mathrm{C}$ and $5 \% \mathrm{CO}_{2}$. Analysis was performed using the tracking module of the AxioVision 4.8 software. At least 25 cells per view field were tracked for $6 \mathrm{~h}$; cells undergoing division or apoptosis were excluded from analyses. The persistent random-walk model was used to characterize cell motility [ 19]. For each individual cell, the mean square displacement $\left\langle D^{2}>\right.$ was calculated from the following formula: $<\mathrm{D} 2>=\sum \mathrm{i}=1 \mathrm{M}$ d i $2 \backslash$ documentclass[12pt]\{minimal\} \usepackage\{amsmath\} lusepackage $\{$ wasysym\} lusepackage \{amsfonts\} lusepackage $\{$ amssymb\} \usepackage $\{$ amsbsy\} lusepackage \{mathrsfs\} lusepackage \{upgreek\} Isetlength\{loddsidemargin\}\{-69pt\} \begin \{document } \$ \$ $<\{\mathrm{D}\}^{\wedge} 2>=\left\{\backslash\right.$ displaystyle $\backslash$ sum_ $\left.\{\mathrm{i}=1\}^{\wedge} \mathrm{M}\{\mathrm{d}\}_{-} \mathrm{i}^{\wedge} 2\right\}$ \$ lend $\{$ document $\}$

where $\mathrm{d}_{\mathrm{i}}$ is the displacement of a cell from its initial position at time level $\mathrm{t}_{\mathrm{i}}$. The persistence time $(\mathrm{P})$ (i.e. average time interval between significant movements and direction changes) and random motility coefficient $(\mu)$ (i.e. the rate at which a cell population is able to migrate into and colonize a new area) were deduced from the $\left\langle\mathrm{D}^{2}>\right.$ value and the cell velocity (S), using the following formulas: $\langle\mathrm{D}\rangle=2 \mathrm{~S}$ $2 \mathrm{P} 21 / \mathrm{P}-1+\exp -1 / \mathrm{P} \mu=1 / 2 \mathrm{~S} 2 \mathrm{P} \backslash$ documentclass[12pt]\{minimal\} lusepackage\{amsmath lusepackage \{wasysym\} lusepackage\{amsfonts\} lusepackage \{amssymb\} \usepackage \{amsbsy\} lusepackage \{mathrsfs\} lusepackage \{upgreek\} \setlength\{loddsidemargin $\}\{-69 \mathrm{pt}\} \backslash$ begin $\{$ document $\$ \$$ $\backslash$ begin $\{$ array $\}\{\mathrm{c}\} \backslash h$ fill $<\mathrm{D}>=2\{\backslash \text { mathrm }\{\mathrm{S}\}\}^{\wedge} 2\{\backslash \operatorname{mathrm}\{\mathrm{P}\}\}^{\wedge} 2 \backslash$ left $\backslash \operatorname{left}(1 \wedge$ mathrm $\{\mathrm{P}\} \backslash$ right $)-1+\operatorname{lexp}$ $\backslash$ left(-1^mathrm $\{\mathrm{P}\} \backslash$ right $) \backslash$ right $] \backslash h f i l l ~ \\{\} \backslash$ hfill \upmu $=\backslash \operatorname{left}(1 / 2 \backslash$ right $)\{\backslash \text { mathrm }\{\mathrm{S}\}\}^{\wedge} 2 \backslash$ mathrm $\{\mathrm{P}\} \backslash h$ fill lend $\{$ array $\$$ \$lend $\{$ document

\section{Wound healing assay}

An optimized wound healing assay was used as previously described [ 20], with slight modifications. Endothelial cells were grown to confluence in specific culture inserts (Ibidi, Martinsried, Germany). After $24 \mathrm{~h}$, the culture inserts were removed, leaving a definite cell-free gap of approximately $400 \mu \mathrm{m}$, and the cells were washed with PBS before their incubation in culture medium. The colonization of the cell-free gap was analysed by time-lapse videomicroscopy using the $5 \mathrm{X}$ objective of the same microscope device used for immunofluorescence experiments. Photographs were taken every 10 minutes for $20 \mathrm{~h}$ and plates were kept at $37^{\circ} \mathrm{C}$ and $5 \% \mathrm{CO}_{2}$ throughout the duration of the experiment. The migration rate was calculated digitally by quantification of the cell-free area at the different time points using the AxioVision 4.7 software.

\section{In vitro Matrigel $^{\mathrm{TM}}$ assay}

Matrigel $^{\mathrm{TM}}$ (BD Biosciences, North Ryde, Australia) assay was used to determine the effect of $\gamma$-actin knockdown on endothelial cell morphogenesis into capillary tubes, as previously described [ 18]. Briefly, 24-well plates were coated at $4^{\circ} \mathrm{C}$ with $270 \mu \mathrm{L}$ of a Matrigel ${ }^{\mathrm{TM}}$ solution (1:1 dilution in culture medium), which was then allowed to solidify for $1 \mathrm{~h}$ at $37^{\circ} \mathrm{C}$ before cell seeding. Cells were allowed to undergo morphogenesis and form capillary-like structures and photographs were taken after $8 \mathrm{~h}$ using the $5 \mathrm{X}$ objective of the same microscope device used for immunofluorescence experiments.

Angiogenesis was then quantitatively evaluated by measuring the total surface area of capillary tubes formed in at least 10 view fields per well using the AxioVision 4.7 software.

A non-enzymatic methodology was also established to analyse the potential changes in protein expression that occur during the morphological differentiation of endothelial cells into vascular networks. Briefly, $3.2 \times 10^{5}$ cells were seeded onto 6-well plates previously coated with Matrigel ${ }^{\mathrm{TM}}$ and harvested at different time points of the morphological differentiation process (i.e. $15 \mathrm{~min}, 1,2,4$ and $8 \mathrm{~h}$ ). Cells were first incubated with a Cell Recovery Solution (BD Biosciences) for $1 \mathrm{~h}$ at $4^{\circ} \mathrm{C}$ under agitation to allow complete dissolution of the Matrigel ${ }^{\mathrm{TM}}$, then pelleted, washed with cold PBS and finally lysed as described in the western blotting section.

\section{Rho-associated kinase (ROCK) signalling inhibition}

ROCK signalling was interrupted as previously described [ 8], through the use of two specific ROCK inhibitors, H-1152 (Merck Millipore, Kilsyth, Australia) and Y-27632 (Sigma-Aldrich). Stock solutions of both inhibitors were prepared in water and stored at $4^{\circ} \mathrm{C}$. Inhibitors $(1-10 \mu \mathrm{M})$ were added to siRNAtransfected cells at $48 \mathrm{~h}$ post-transfection, and remained in culture medium for a further $24 \mathrm{~h}$ and during wound-healing and angiogenesis assays. 
All experiments were performed at least in triplicate. Statistical significance was determined using twosided student's $t$ test in the GraphPad Prism 4 software (GraphPad Software, Inc).

\section{Results}

\section{Spatial distribution of $\beta$ - and $\gamma$-actin in vascular endothelial cells}

Using specific monoclonal antibodies directed against $\beta$ - and $\gamma$-actin [7], we investigated the cellular distribution of both actin isoforms in two models of vascular endothelial cells (Figure 1). These coimmunofluorescence experiments demonstrated extensive colocalization of the two actin isoforms with some level of spatial preference. In HMEC- 1 and BMH29L endothelial cells, $\beta$ - and $\gamma$-actin signals strongly overlapped but $\beta$-actin signal appeared relatively more enriched in radial stress fibres and membrane ruffling in relation to $\gamma$-actin, which was more uniformly spread across the entire microfilament meshwork. Quantification using the Pearson's Correlation Coefficient method [ 21] confirmed the strong colocalization of $\beta$ - and $\gamma$-actin (Additional file 1: Figure S1A). Furthermore, decreased correlation in some cells was mostly due to variations in stoichiometry in different subcellular structures rather than complete segregation of the two actin isoforms (Additional file 1: Figure S1B).

\section{Figure 1}
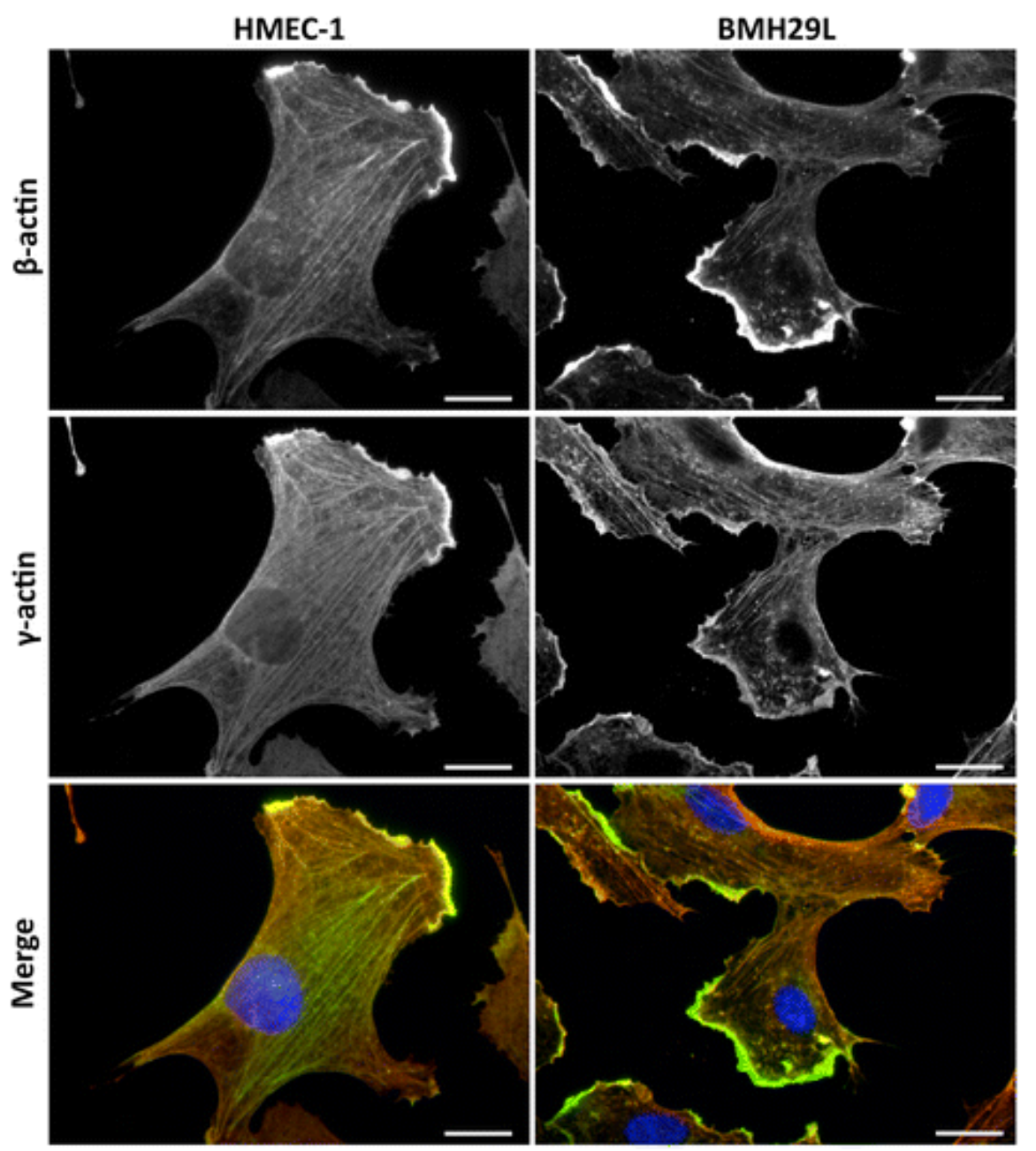

Localization of $\beta$ - and $\gamma$-actin in vascular endothelial cells.Representative photographs of HMEC-1 ( left ) and BMH29L ( right ) endothelial cells stained with $\beta$-actin ( top ) and $\gamma$-actin ( middle) antibodies. The merged photographs ( bottom) show $\beta$-actin in green, $\gamma$-actin in red and DNA (DAPI) in blue. Scale bar , $20 \mu \mathrm{m}$. 
Significant knockdown of $\beta$-actin expression could not be achieved in endothelial cells without major cytotoxicity (data not shown). We therefore focused our attention on the functional analysis of $\gamma$-actin using RNA interference. As shown in Figure 2A, when HMEC-1 cells were transfected with $\gamma$-actin siRNA for $24 \mathrm{~h}$, a $71 \pm 12 \%$ reduction in $\gamma$-actin gene expression was observed by quantitative RT-PCR $(\mathrm{p}<0.01)$. Consistently, a 50-60\% knockdown of $\gamma$-actin expression was observed at the protein level after $72 \mathrm{~h}$ transfection in both HMEC-1 and BMH29L cells (Figure $2 \mathrm{~B}$ and $\mathrm{C} ; \mathrm{p}<0.001$ ). Western blot analysis also showed that this level of $\gamma$-actin knockdown could be achieved without any significant compensatory changes in $\beta$-actin expression.

Figure 2

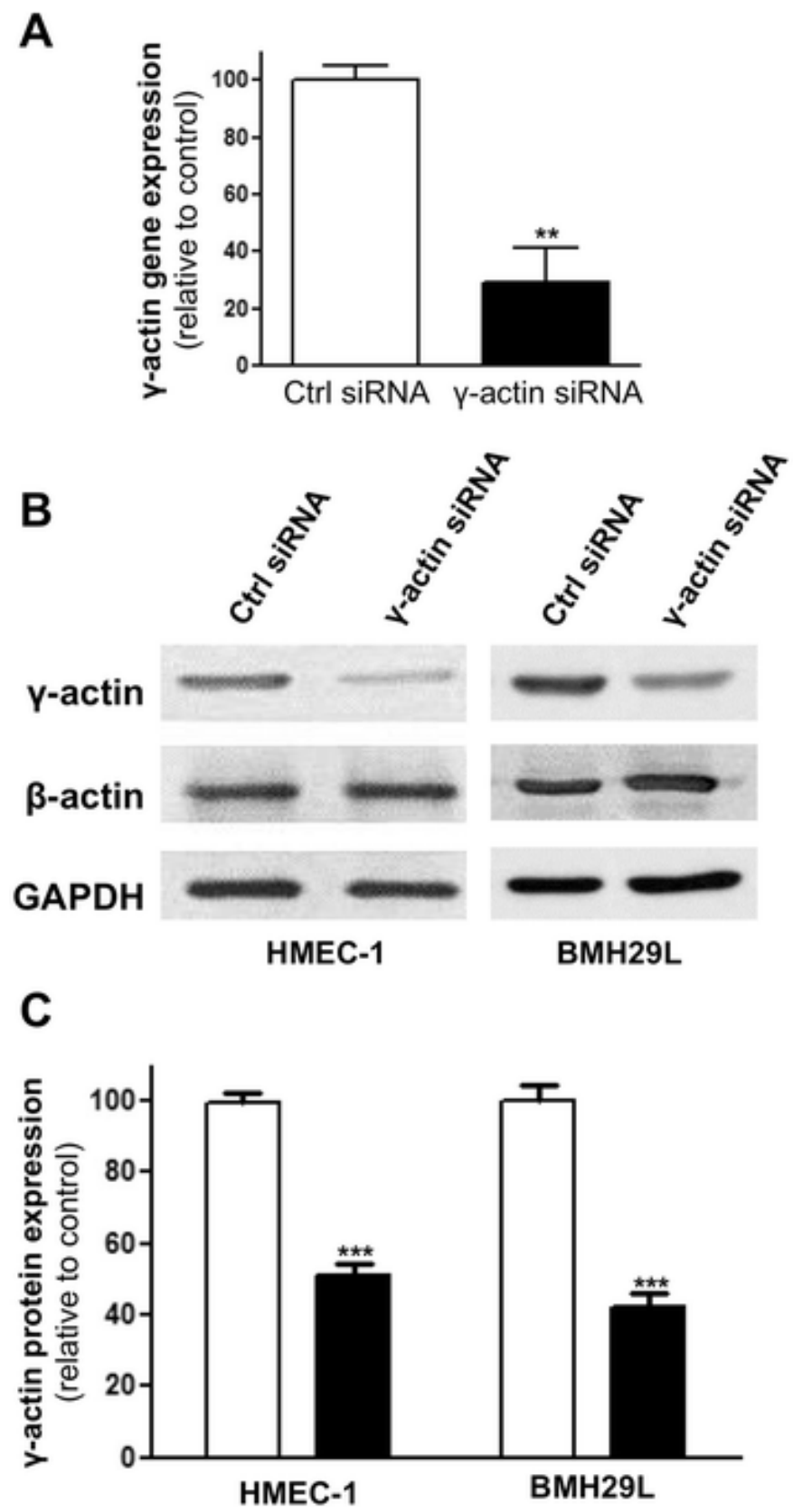

$\gamma$-actin knockdown in vascular endothelial cells. (A)Histogram showing $\gamma$-actin relative gene expression following treatment with control (white) and $\gamma$-actin siRNA (black) for $24 \mathrm{~h}$ as assessed by quantitative RT-PCR. $\beta$ 2-microglobulin was used as housekeeping gene. Columns, means of at least three individual experiments; bars, SE. Statistics were calculated by comparing $\gamma$-actin relative expression in control and $\gamma$-actin siRNA-treated HMEC-1 cells; **, p $<0.01$. (B)Representative immunoblots of HMEC-1 ( left ) and BMH29L ( right) cell lysates following treatment with control and $\gamma$-actin siRNA for $72 \mathrm{~h}$. Membranes were probed with anti- $\beta$-actin, anti- $\gamma$-actin and anti-GAPDH (loading control) antibodies. (C)Histogram showing the relative protein expression $\gamma$-actin as determined by densitometry after normalization with GAPDH, following treatment with control ( white ) and $\gamma$-actin siRNA ( black) for 72 h. Columns, means of at least four individual experiments; 
bars , SE. Statistics were calculated by comparing $\gamma$-actin expression level in control and $\gamma$-actin siRNA-treated cells; $* * *, p<0.001$.

Co-immunofluorescence staining was then used to analyse the effects of $\gamma$-actin knockdown on the localization of actin isoforms. In $\gamma$-actin siRNA-treated HMEC-1 cells, qualitative data revealed that the dense cortical actin meshwork was partially depleted in $\gamma$-actin and the remaining $\gamma$-actin was mostly found in stress fibres (Figure 3 ). In contrast, $\beta$-actin distribution was unaltered. Similar effects were observed in BMH29L cells (Additional file 2: Figure S2). Interestingly, quantitative analysis showed that $\gamma$-actin knockdown resulted in a slight increase in correlation of the $\beta$ - and $\gamma$-actin signals, which was mostly due to decreased variation in stoichiometry (Additional file 1: Figure S1; Pearson coefficient of $0.75 \pm 0.02$ and $0.86 \pm 0.01$ in control and $\gamma$-actin siRNA-treated cells, respectively; $p<0.001)$.

\section{Figure 3}

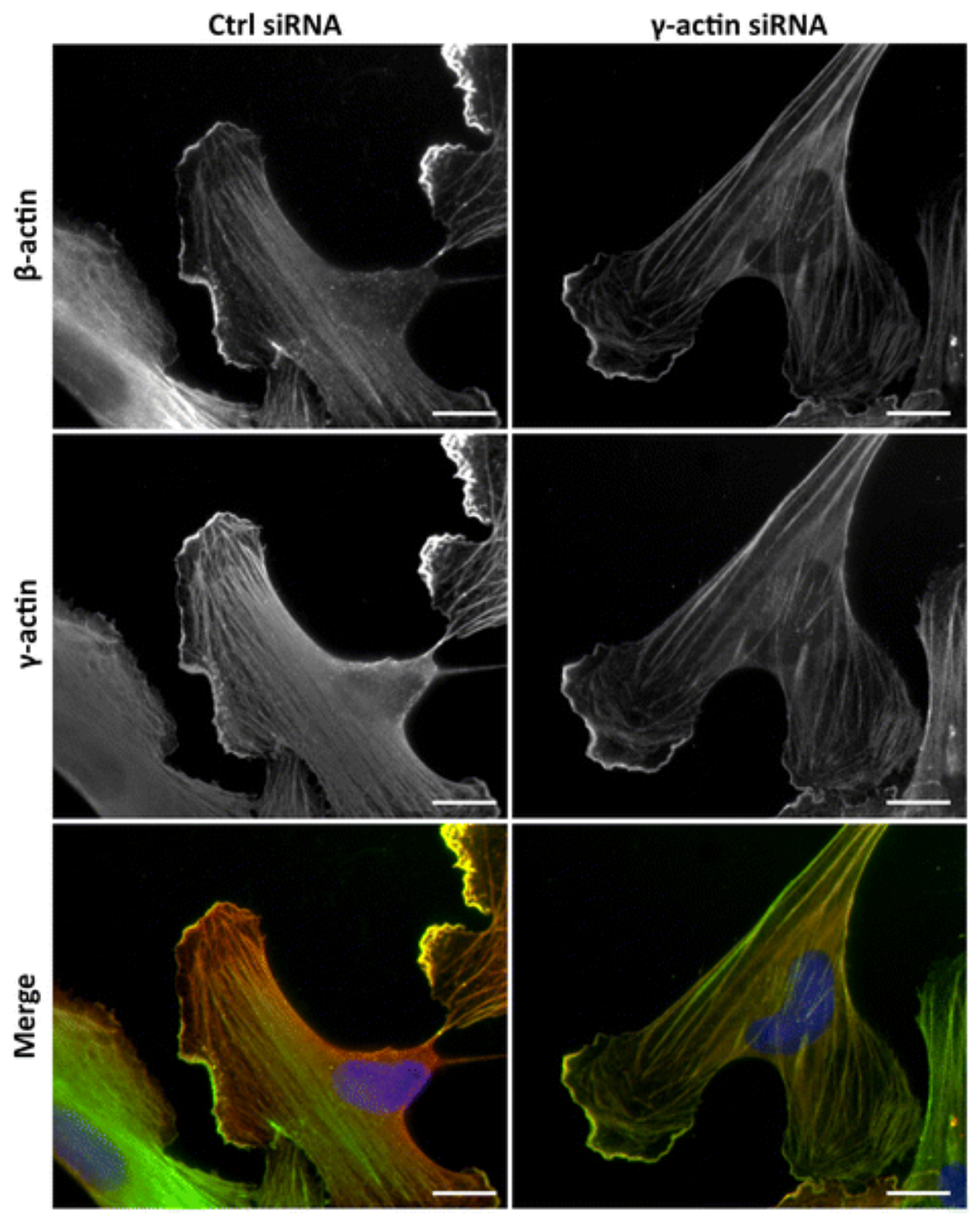

Effect of $\gamma$-actin knockdown on the localization of $\beta$ - and $\gamma$-actin.Representative photographs of HMEC-1 endothelial cells treated for $72 \mathrm{~h}$ with control ( left ) or $\gamma$-actin siRNA ( right) and stained with $\beta$-actin ( top ) and $\gamma$-actin ( middle ) antibodies. The merged photographs ( bottom ) show $\beta$ actin in green, $\gamma$-actin in red and DNA (DAPI) in blue. Scale bar , $20 \mu \mathrm{m}$.

\section{Cytoplasmic $\gamma$-actin expression is essential for the morphological differentiation of endothelial cells into vascular networks}

Matrigel $^{\mathrm{TM}}$ assay was used to investigate the role of $\gamma$-actin in angiogenesis in vitro. Photographs taken after 8 hour incubation on Matrigel ${ }^{\mathrm{TM}}$ revealed that knocking down $\gamma$-actin expression almost completely suppressed the formation of capillary-like structures (Figure 4A). Quantitative analysis showed that $\gamma$ - 
actin knockdown inhibited the morphological differentiation of HMEC- 1 and BMH29L cells by $89.5 \pm$ $2.7 \%$ and $72.0 \pm 6.7 \%$, respectively (Figure $4 \mathrm{~B} ; \mathrm{p}<0.001$ ). Similar results were obtained when HMEC1 cells were transfected for $72 \mathrm{~h}$ with a different $\gamma$-actin siRNA sequence (Additional file 3: Figure S3). Time-lapse videomicroscopy experiments revealed that $\gamma$-actin siRNA-treated cells initiated the formation of capillary-like tubes on Matrigel ${ }^{\mathrm{TM}}$ but could not maintain these vascular networks, which rapidly regressed (Additional file 4: supplementary videos 1-2). This demonstrates that $\gamma$-actin is dispensable in the early steps of angiogenesis but required for neovessel maintenance.

\section{Figure 4}

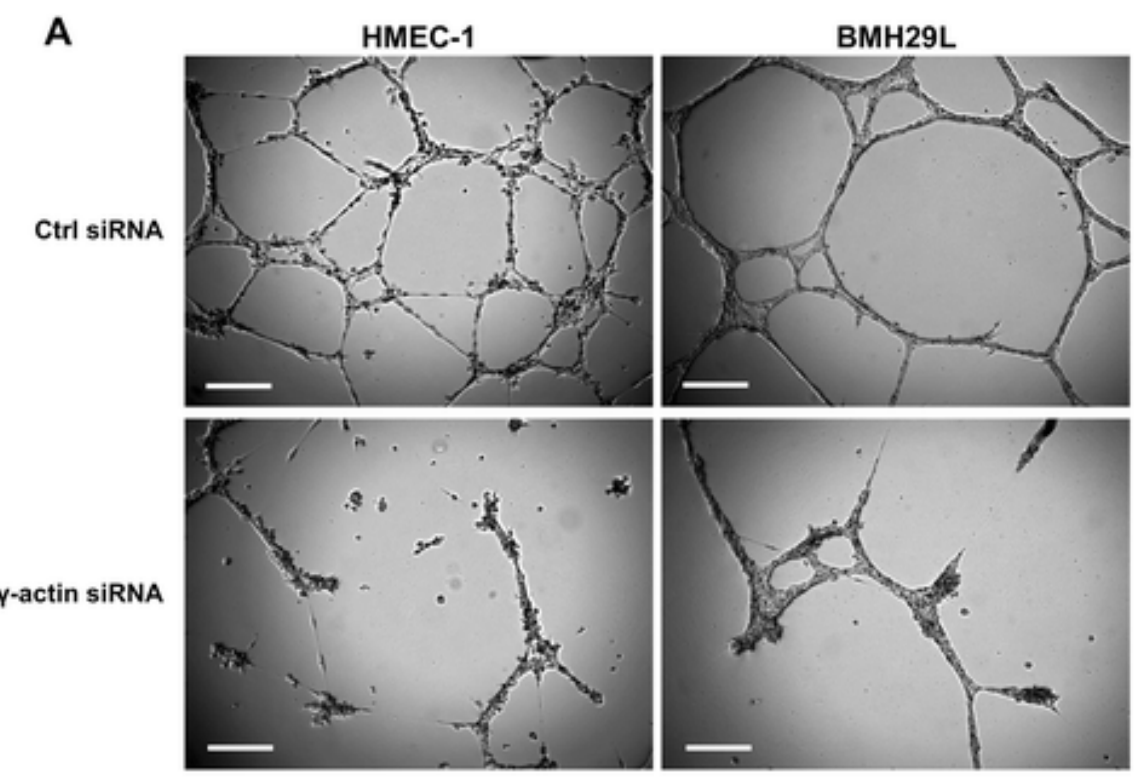

B

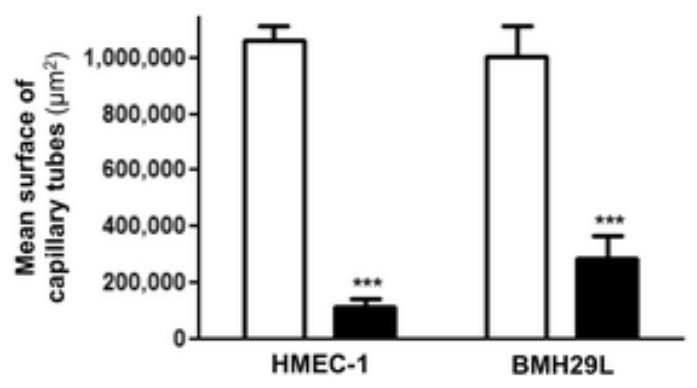

Effect of $\gamma$-actin knockdown on the formation vascular networks in vitro. (A)Representative photographs of HMEC-1 ( left ) and BMH29L cells ( right ) incubated for $8 \mathrm{~h}$ on Matrigel $^{\mathrm{TM}}$. Cells were treated either with control ( top ) or $\gamma$-actin siRNA ( bottom ) for $72 \mathrm{~h}$. Scale bar , $250 \mu \mathrm{m}$. (B)Histogram showing the surface occupied by vascular networks following treatment with control ( white ) and $\gamma$-actin siRNA ( black) for $72 \mathrm{~h}$. Columns, means of at least four individual experiments; bars, SE. Statistics were calculated by comparing the mean surface occupied by vascular networks per view field (at least 10 view fields per condition) for control siRNA- and $\gamma$-actin siRNA-treated cells. $* * *, p<0.001$.

\section{Vascular regression induced by $\boldsymbol{\gamma}$-actin knockdown is associated with impaired VE-cadherin up-regulation}

Endothelial cells were harvested non-enzymatically at different time points of the morphological differentiation process on Matrigel ${ }^{\mathrm{TM}}$ (Figure 5A) to investigate potential changes in expression of $\gamma$ actin, endothelial cell-to-cell contact protein VE-cadherin and major angiogenesis receptor VEGFR-2 by western blotting. While there was no significant change in $\gamma$-actin expression during the morphological differentiation of endothelial cells, VE-cadherin expression was gradually up-regulated (Figure $5 \mathrm{~B}$ ). Densitometry analysis revealed a 5-fold increase in VE-cadherin relative expression in control siRNAtreated cells between $15 \mathrm{~min}$ and $8 \mathrm{~h}$ incubation on Matrigel $^{\mathrm{TM}}$ (Figure $5 \mathrm{C} ; \mathrm{p}<0.001$ ). Interestingly, $\gamma$ actin knockdown significantly impaired VE-cadherin up-regulation (Figure $5 \mathrm{~B}$ and $\mathrm{C}$ ). Although there 
was no significant difference in VE-cadherin expression between control siRNA- and $\gamma$-actin siRNAtreated cells at steady state when cells were grown on plastic (Additional file 5: Figure S4A), the levels of VE-cadherin expression were significantly lower in $\gamma$-actin siRNA-treated cells at all time points of the morphological differentiation process on Matrigel ${ }^{\mathrm{TM}}$ except at $4 \mathrm{~h}$ (Figure $5 \mathrm{C}$ ). Additional western blot analysis further revealed that the expression of VEGFR-2 was also up-regulated during morphological differentiation, but this up-regulation was not affected by $\gamma$-actin knockdown (Additional file 5: Figure S4B). This suggests that the up-regulation of VE-cadherin expression, but not VEGFR-2, is dependent upon adequate $\gamma$-actin expression.

\section{Figure 5}

A

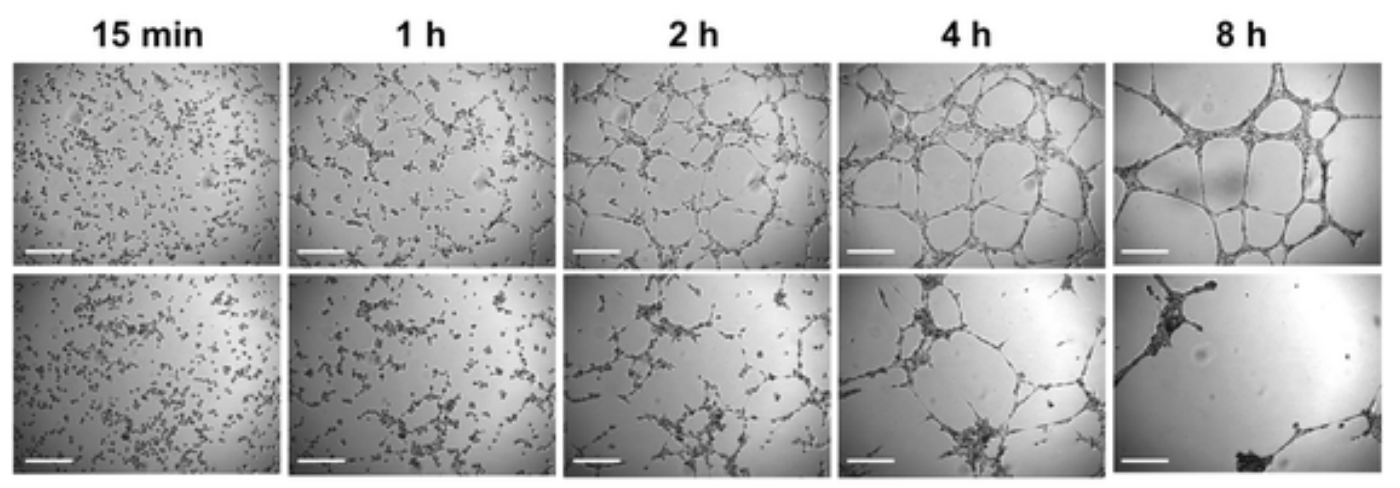

B

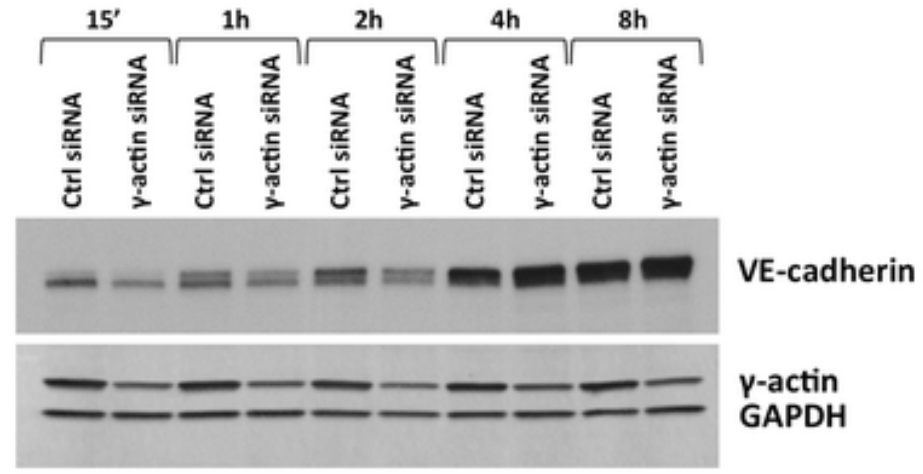

C

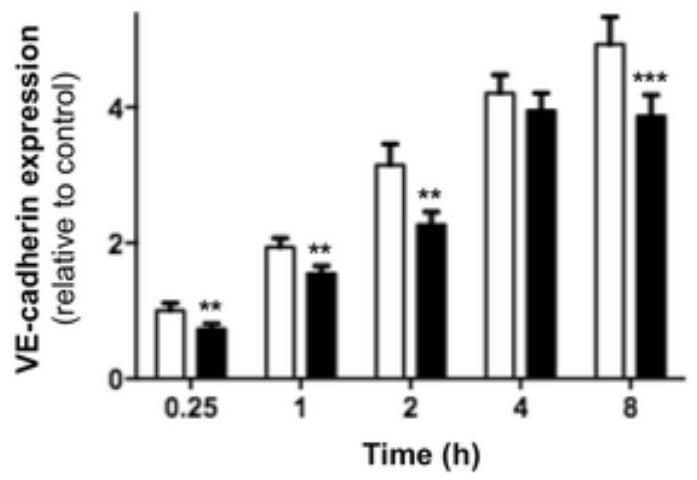

Effect of $\gamma$-actin knockdown on VE-cadherin expression during morphological differentiation of endothelial cells into vascular networks. (A)Representative photographs of HMEC-1 cells at various time points of the morphological differentiation process on Matrigel ${ }^{\mathrm{TM}}$, following treatment with control ( top ) and $\gamma$-actin siRNA ( bottom ) for $72 \mathrm{~h}$. Scale bar , $250 \mu \mathrm{m}$. (B)Representative immunoblots of HMEC-1 cell lysates obtained at different time points of the morphological differentiation process on Matrigel ${ }^{\mathrm{TM}}$, following treatment with control and $\gamma$-actin siRNA for $72 \mathrm{~h}$. Membranes were probed with anti-VE-cadherin, anti- $\gamma$-actin and anti-GAPDH (loading control) antibodies. (C)Histogram showing the relative protein expression of VE-cadherin as determined by densitometry after normalization with GAPDH (loading control), following treatment with control ( white ) and $\gamma$-actin siRNA ( black) for $72 \mathrm{~h}$. Columns, means of at least four individual experiments; 
bars , SE. Statistics were calculated by comparing VE-cadherin expression level in control and $\gamma$ actin siRNA-treated HMEC-1 cells; $* *, p<0.01 ; * * *, p<0.001$.

\section{Cytoplasmic $\gamma$-actin plays a key role in endothelial cell motility and chemotaxis}

To investigate the effects of $\gamma$-actin knockdown on the pro-angiogenic functions of endothelial cells, a panel of cell biology assays was used. First, we found that knocking down $\gamma$-actin expression did not significantly affect the adhesion of endothelial cells to various substrates, including major ECM proteins fibronectin, laminin and collagen I (Figure 6A). In contrast, knocking down $\gamma$-actin expression significantly impaired the chemotactic response of endothelial cells to various chemo-attractants. As shown in Figure 6B, addition of FCS, VEGF, FGF $\beta$ or ECGF in the bottom well of the Boyden chamber resulted in a significant increase in migration of control siRNA-treated HMEC-1 cells, as compared to the negative control (absence of FCS; $p<0.05$ ). This increase in cell migration was significantly inhibited when HMEC-1 cells were transfected with $\gamma$-actin siRNA $(\mathrm{p}<0.05)$. Interestingly, FGF $\beta^{-}$ induced migration was completely suppressed by $\gamma$-actin knockdown, while migration induced by other chemo-attractants was only partially reduced.

\section{Figure 6}
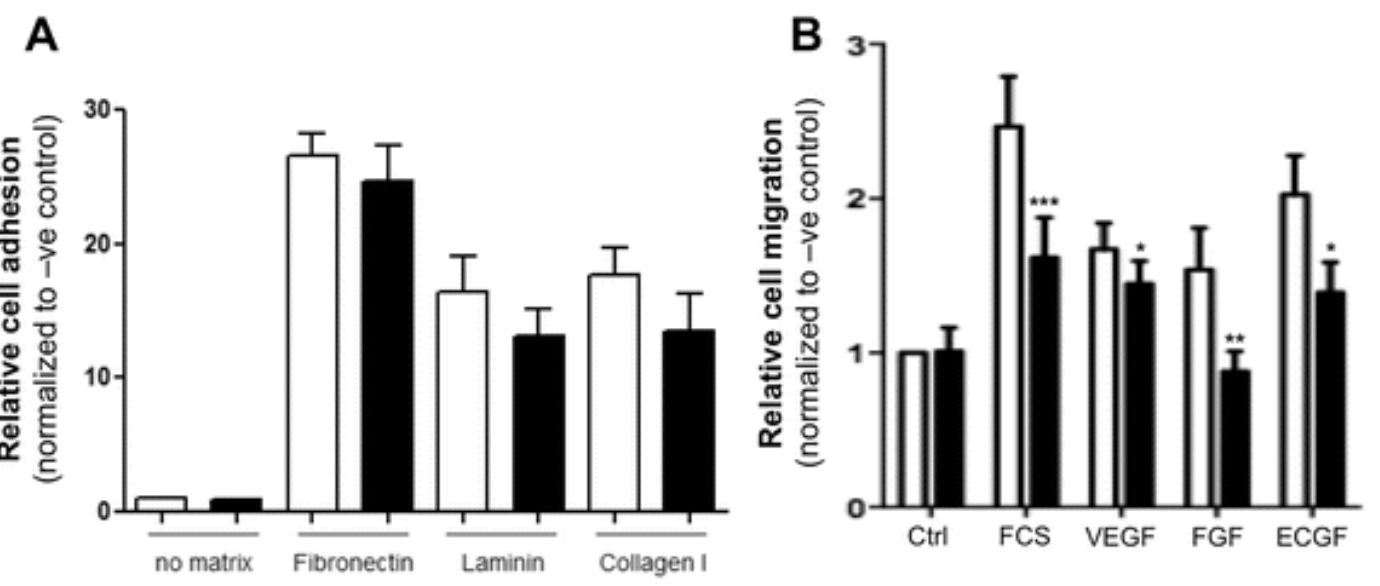

C
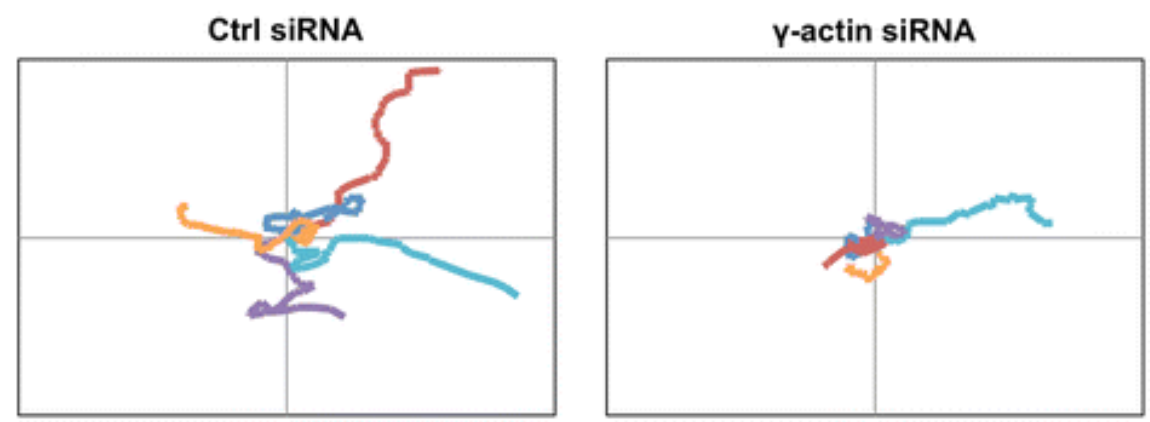

D
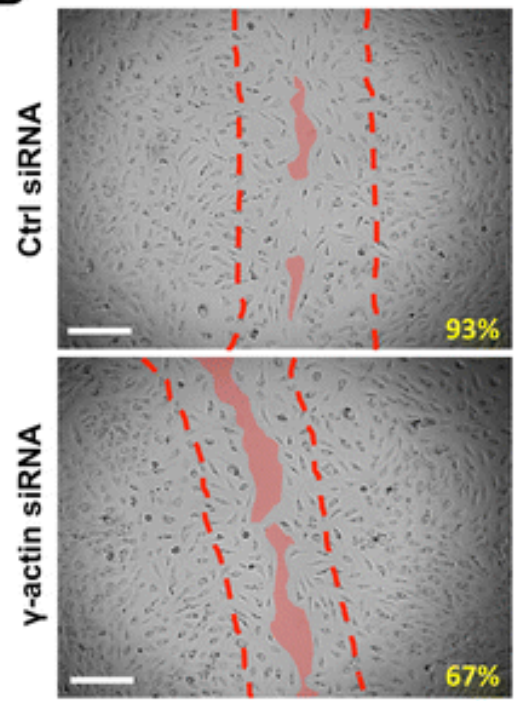

E

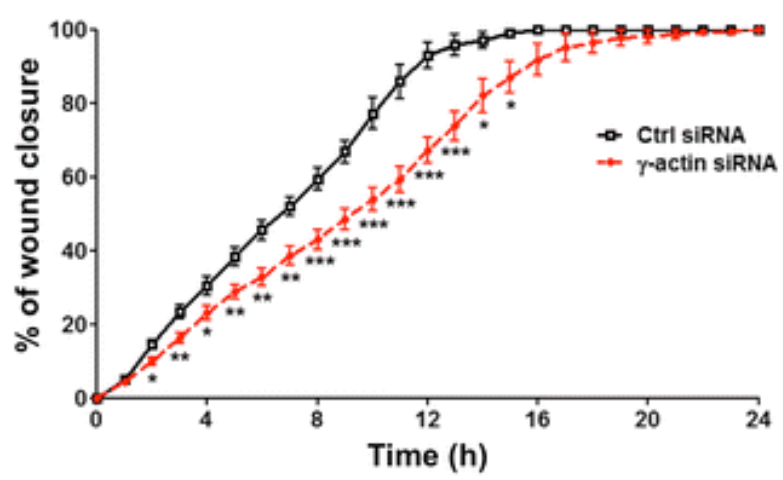


Effect of $\gamma$-actin knockdown on cell adhesion, migration and motility. (A)Histogram showing the relative adhesion of endothelial cells following treatment with control ( white) and $\gamma$-actin siRNA ( black ) for $72 \mathrm{~h}$. Fluorescently labeled HMEC-1 cells were allowed to adhere to various substrates for 1 h. Columns, means of at least three individual experiments; bars, SE. (B)Histogram showing the relative migration of endothelial cells towards FCS, VEGF, FGF $\beta$ and ECGF following treatment with control ( white) and $\gamma$-actin siRNA ( black) for $72 \mathrm{~h}$. Fluorescently labeled HMEC-1 cells were allowed to migrate through $8 \mu \mathrm{m}$ pore PET membrane and towards a chemo-attractant for $6 \mathrm{~h}$. Columns, means of at least four individual experiments; bars, SE. Statistics were calculated by comparing the fluorescence measured at 492/517 (Abs/Em) with control and $\gamma$-actin siRNA-treated cells; *, p $<0.05 ; * *, \mathrm{p}<0.001$. (C)Representative trajectories of 5 individual HMEC-1 cells, recorded by time-lapse videomicroscopy over $6 \mathrm{~h}$, following treatment with control ( left) and $\gamma$ actin siRNA ( right) for $72 \mathrm{~h}$. Scale,$-130 \mu \mathrm{m}$ to $+130 \mu \mathrm{m}$ for both $\mathrm{x}$ and y axes. (D)Representative photographs of control ( top ) and $\gamma$-actin siRNA-treated ( bottom ) BMH29L cells in wound healing experiments, taken $12 \mathrm{~h}$ after start of experiment. Broken lines show the position of the initial cellfree gap (at time 0 ) and solid lines highlight the position of the migration edge after $12 \mathrm{~h}$. Inset, \% of wound closure. (E)Graph showing the percentage of wound recovery as a function of time for control ( black, solid line) and $\gamma$-actin siRNA-treated ( red, broken line ) BMH29L cells. Points, means of at least four individual experiments; bars, SE. Statistics were calculated by comparing control and $\gamma$ actin siRNA-treated cells at specific time points; *, $\mathrm{p}<0.05 ; *^{*}, \mathrm{p}<0.01 ; * * *, \mathrm{p}<0.001$.

The effect of $\gamma$-actin knockdown on the random motility of endothelial cells was then assessed by timelapse videomicroscopy experiments. Figure $6 \mathrm{C}$ shows the representative trajectories of 5 cells transfected with either control ( left panel) or $\gamma$-actin siRNA ( right panel). While control siRNAtreated cells randomly explored their micro-environment, $\gamma$-actin siRNA-treated cells appeared to stay focused around the same area. Analysis using the persistent random walk model [ 19] revealed that $\gamma$ actin knockdown decreased the average cell velocity and increased the time endothelial cells spent not moving as evidenced by an increase in persistence time (Table 1). As a result, $\gamma$-actin knockdown reduced the capacity of endothelial cells to explore their environment as shown by a decrease in random motility coefficient (i.e. the rate at which a cell will migrate into a new area and colonize it).

\section{Table 1}

Effects of $\gamma$-actin knockdown on random motility parameters

\begin{tabular}{l|l|l|l}
\hline \multicolumn{1}{c|}{ Parameters } & Control siRNA & $\boldsymbol{\gamma}$-actin siRNA & \multicolumn{1}{c}{$\%$ change } \\
\hline Average cell velocity $(\mu \mathrm{m} / \mathrm{min})$ & $0.53 \pm 0.03$ & $0.37 \pm 0.03$ & $-30 \pm 5 \% * *$ \\
Persistence time $(\mathrm{min})$ & $6.3 \pm 0.3$ & $8.6 \pm 0.6$ & $+36 \pm 7 \% *$ \\
Random motility coefficient $\left(\mu \mathrm{m}^{2} / \mathrm{min}\right)$ & $0.90 \pm 0.05$ & $0.55 \pm 0.07$ & $-38 \pm 8 \% * *$ \\
\hline
\end{tabular}

At least 25 individual cells were analysed per view field using the persistence random-walk model [ 19]. Values are average of four individual experiments \pm SEM. Statistics were calculated by comparing control and $\gamma$-actin siRNA-treated cells: *, p $<0.05 ; * *, p<0.01$.

In order to further investigate the effects of $\gamma$-actin knockdown on endothelial cell migration, wound healing experiments were performed using time-lapse videomicroscopy. Figure 6D shows representative photographs taken from control (top panel) and $\gamma$-actin siRNA-treated cells ( bottom panel ) after $12 \mathrm{~h}$ incubation. At this time point, recovery from the wound was $93.0 \pm 3.4 \%$ and $67.2 \pm$ $3.5 \%$ in control and $\gamma$-actin siRNA-treated cells, respectively $(\mathrm{p}<0.001)$. As shown in Figure $6 \mathrm{E}, \gamma$ actin knockdown resulted in a significant decrease in wound recovery at all time points until $15 \mathrm{~h}$. Linear regression analysis showed that control siRNA-treated BMH29L cells reached 50\% wound recovery after $6.7 \pm 0.4 \mathrm{~h}$, whereas it took $9.4 \pm 0.6 \mathrm{~h}(\mathrm{p}<0.01)$ to $\gamma$-actin siRNA-treated BMH29L cells (data not shown). Similar results were obtained with HMEC-1 cells, which took $7.8 \pm 0.5 \mathrm{~h}$ and $9.8 \pm 0.5 \mathrm{~h}$ to reach $50 \%$ wound recovery $(\mathrm{p}<0.01)$, when they were transfected with control and $\gamma$-actin siRNA, respectively (data not shown).

\section{Cytoplasmic $\gamma$-actin regulates endothelial cell motility through ROCK signalling pathway}

In order to gain more insights into the role of $\gamma$-actin in endothelial cell motility, we investigated potential changes in the organisation of microtubules, actin stress fibres and focal adhesions as a result 
of $\gamma$-actin knockdown. Tubulin staining of endothelial cells showed no significant change in the general organisation of the microtubule network as a result of $\gamma$-actin knockdown (Additional file 6: Figure S5). In contrast, co-immunofluorescence experiments with phalloidin and anti-paxillin antibody demonstrated that transfection of endothelial cells with $\gamma$-actin siRNA led to an accumulation of thick actin stress

fibres and large paxillin-containing focal adhesions (Figure $7 \mathrm{~A}$ ). Quantitative analysis revealed that $\gamma$ actin knockdown induced a 38\% increase in the average thickness of actin stress fibres, which was 0.75 $\pm 0.15 \mu \mathrm{m}$ and $1.04 \pm 0.17 \mu \mathrm{m}$ in control and $\gamma$-actin siRNA-treated cells, respectively (Figure $7 \mathrm{~B} ; \mathrm{p}<$ 0.001 ). This demonstrates that $\gamma$-actin knockdown results in a change in filamentous actin (F-actin) structures as a result of changing the $\beta$ - to $\gamma$-actin ratio. Control siRNA-treated cells displayed uniform paxillin staining with small focal adhesions located throughout the cytoplasm and in the lamellipodia. In sharp contrast, $\gamma$-actin siRNA-treated cells showed larger focal adhesions dispersed throughout the cell periphery. Quantitative analysis showed that $\gamma$-actin knockdown did not alter the number of paxillincontaining adhesions but significantly increased their average size by $76 \%$, from $0.96 \pm 0.08 \mu \mathrm{m}^{2}$ to 1.67 $\pm 0.11 \mu \mathrm{m}^{2}$ (Figure $7 \mathrm{C} ; \mathrm{p}<0.001$ ). This accumulation of thick actin stress fibres and large focal adhesions could result from sustained activation of ROCK signalling [ 8]. Western blot analysis revealed that $\gamma$-actin knockdown was associated with a 58\% increase in phosphorylation of myosin light chain 2 (Figure $7 \mathrm{D}-\mathrm{E}$ ), thus confirming activation of the ROCK pathway.

\section{Figure 7}



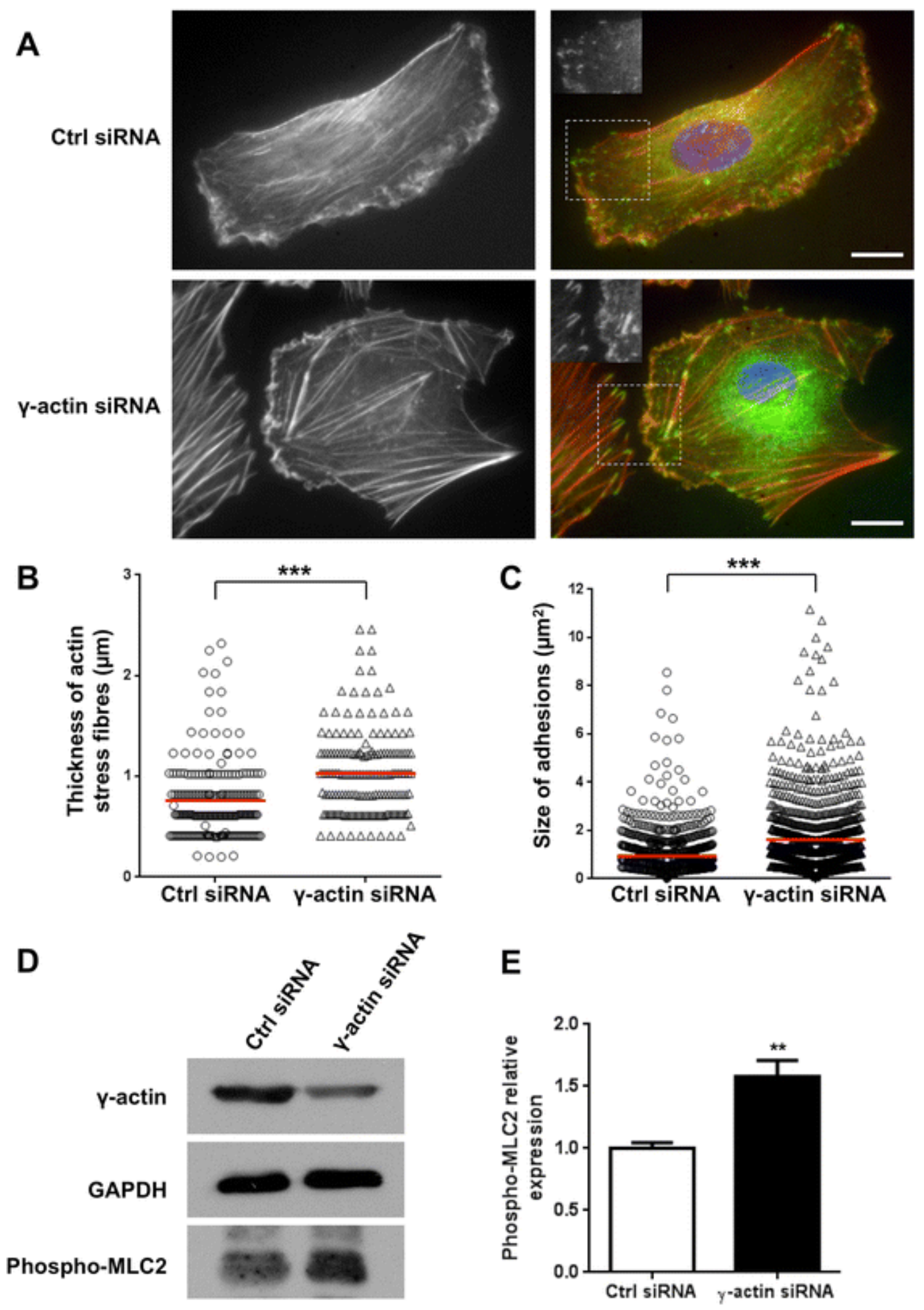

Effect of $\gamma$-actin knockdown on ROCK signalling. (A)Representative photographs of HMEC-1 endothelial cells treated for $72 \mathrm{~h}$ with control ( top ) or $\gamma$-actin siRNA ( bottom) and co-stained with phalloidin ( left ) and anti-paxillin antibody. The merged photographs ( right ) show phalloidin in red, paxillin in green and DNA (DAPI) in blue. Inset shows a magnified view of paxillin staining in the lamellipodial region. Scale bar , $20 \mu \mathrm{m}$. (B-C)Scatter dot plots showing the thickness of actin stress fibres and the size of paxillin-containing adhesions in HMEC-1 endothelial cells treated for $72 \mathrm{~h}$ with control (o) or $\gamma$-actin siRNA $(\Delta)$. Bars, means of at least 15 individual cells. (D)Representative immunoblots of HMEC-1 cell lysates following treatment with control and $\gamma$-actin siRNA for $72 \mathrm{~h}$. Membranes were probed with anti- $\gamma$-actin, anti-GAPDH (loading control) and anti-phospho-myosin light chain 2 antibodies. (E)Histogram showing the relative levels of phosphorylated myosin light chain 2 in HMEC-1 cells following treatment with control ( white) and $\gamma$-actin siRNA (black) for 72 h. Columns, means of at least four individual experiments; bars, SE. Statistics were calculated by comparing control siRNA- versus $\gamma$-actin siRNA-transfected cells. ${ }^{* *}, \mathrm{p}<0.01$; ${ }^{* * *}, \mathrm{p}<0.001$. 


\section{Cytoplasmic $\gamma$-actin regulates angiogenesis through ROCK-dependent and ROCK-independent mechanisms}

Pharmacological inhibition of ROCK signalling showed that the impairment of motility induced by $\gamma$ actin knockdown was entirely dependent upon ROCK activation (Figure $8 \mathrm{~A}$ ). Indeed, incubation with H-1152 and Y-27632 inhibitors completely restored the motility of $\gamma$-actin siRNA-treated HMEC-1 cells. Similar results were obtained with BMH29L cells (Additional file 7: Figure S6). In contrast with the complete rescue of the $\gamma$-actin knockdown motility phenotype by ROCK inhibitors, the capacity of $\gamma$ actin siRNA-treated cells to form and maintain vascular networks on Matrige $^{\mathrm{TM}}$ was only partially restored by ROCK inhibition (Figure 8B-D). Incubation of control siRNA-treated HMEC-1 cells with H-1152 and Y-27362 increased vascular sprouting and therefore led to the formation of more but significantly smaller capillary-like tubes, resulting in a marginal decrease in total vascular surface (4-6\% decrease as compared to control untreated cells). The angiogenic potential of $\gamma$-actin siRNA-treated cells was improved when ROCK signalling was inhibited but vascular regression was not entirely prevented (Figure 8B). In $\gamma$-actin knockdown HMEC-1 cells, angiogenesis inhibition was thus reduced from $75 \pm$ $6 \%$ in untreated cells to $38 \pm 8 \%$ and $26 \pm 8 \%$ in cells incubated with $\mathrm{H}-1152$ and Y-27632, respectively (Figure $8 \mathrm{C} ; \mathrm{p}<0.001$ ). Quantification of the number of vascular networks formed confirmed that incubation with H-1152 and Y-27362 increased vascular sprouting (Figure $8 \mathrm{D} ; \mathrm{p}<0.001$ ) but $\gamma$-actin knockdown still resulted in significantly less networks formed in all conditions. Partial rescue of the angiogenesis suppression induced by $\gamma$-actin knockdown was also observed in BMH29L cells as a result of ROCK inhibition (Additional file 8: Figure S7). Collectively, the results of our study show that $\gamma$ actin plays a key role in the morphological differentiation of endothelial cells into vascular networks, through both ROCK-dependent and ROCK-independent mechanisms.

\section{Figure 8}



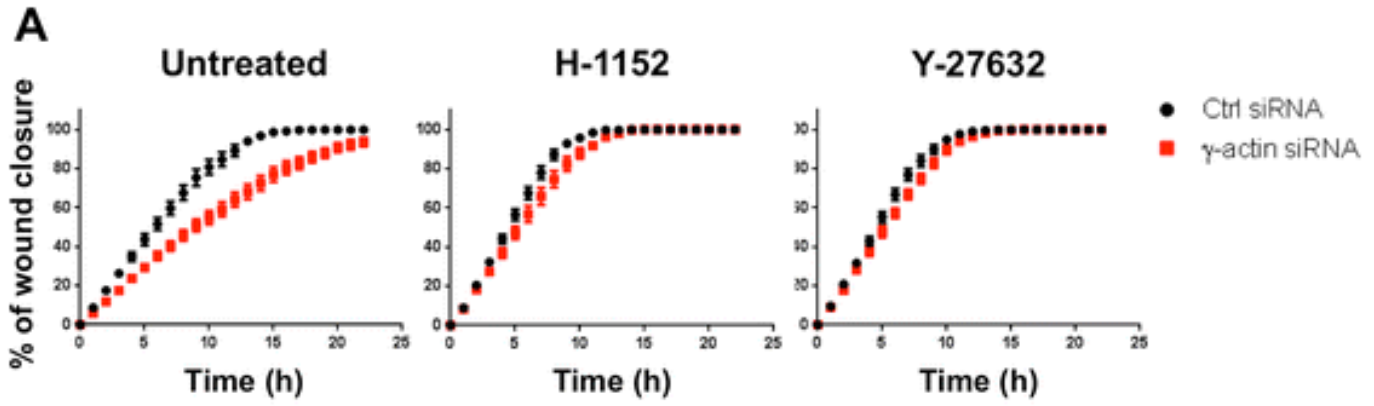

\section{B Untreated}

$\mathrm{H}-1152$
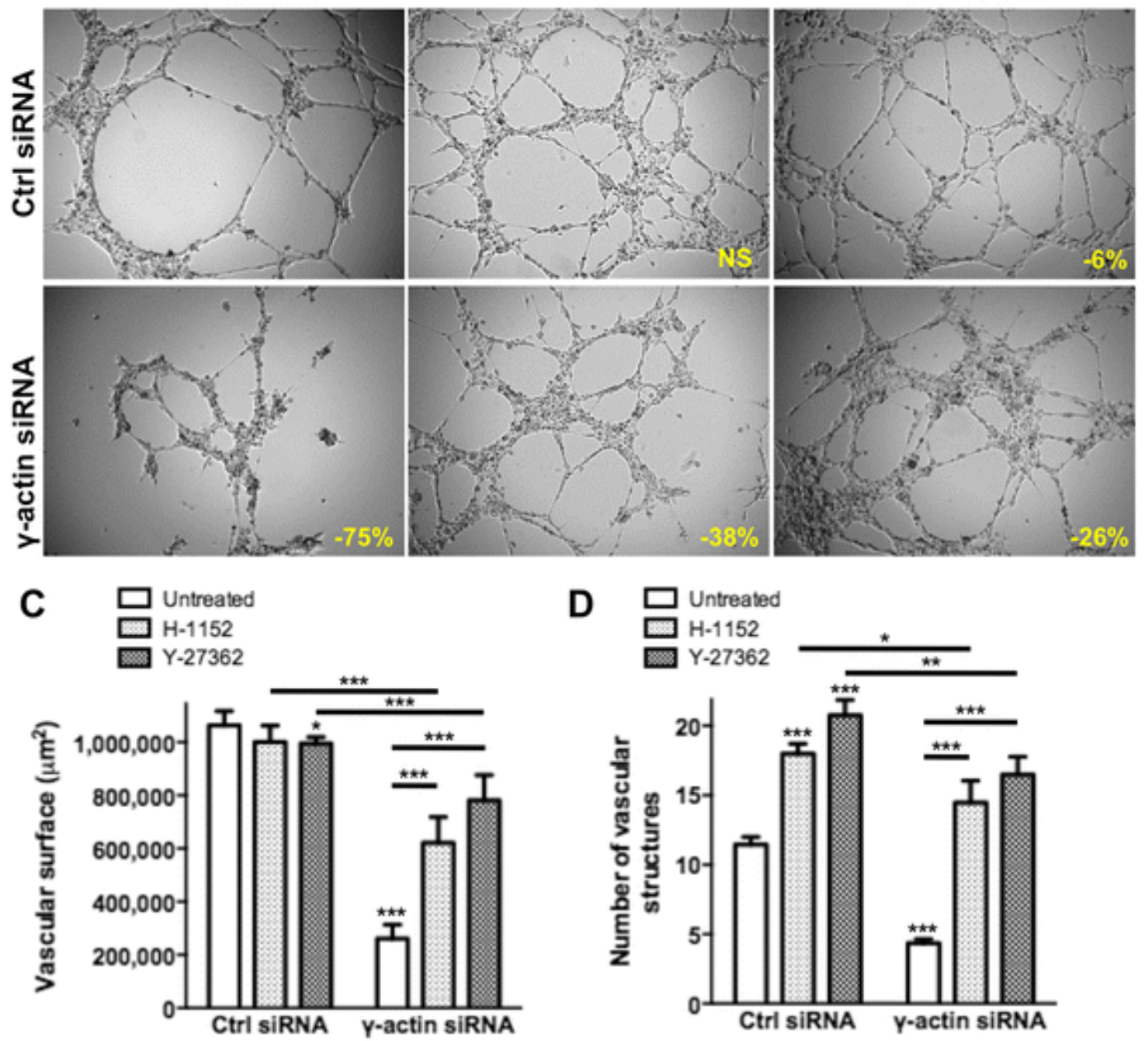

Effect of ROCK signalling inhibition on $\gamma$-actin knockdown-induced vascular regression. (A)Graph showing the percentage of wound recovery as a function of time for control (black) and $\gamma$-actin knockdown ( red ) HMEC-1 cells, either untreated ( left ) or treated with ROCK inhibitors, H-1152 ( middle ) or Y-27632 ( right) at 1 and $10 \mu \mathrm{M}$, respectively. Points , means of at least four individual experiments; bars , SE. (B)Representative photographs of HMEC-1 cells incubated for $8 \mathrm{~h}$ on Matrigel $^{\mathrm{TM}}$. Cells were transfected with either control ( top ) or $\gamma$-actin siRNA ( bottom) for $72 \mathrm{~h}$ and either untreated ( left) or treated with ROCK inhibitors, H-1152 (middle ) or Y-27632 ( right) at 1 and $10 \mu \mathrm{M}$, respectively. Inset, $\%$ of angiogenesis inhibition as compared to untreated control cells. Scale bar , $250 \mu \mathrm{m}$. (C-D)Histograms showing the surface occupied by and the number of vascular networks formed by control and $\gamma$-actin siRNA-transfected HMEC-1 cells following treatment with ROCK inhibitors. Columns, means of at least four individual experiments; bars , SE. Statistics were calculated by comparing the mean surface occupied by vascular networks and the mean number of vascular networks per view field (at least 10 view fields per condition) for control siRNA- versus $\gamma$-actin siRNA-transfected cells unless indicated otherwise. ${ }^{*}, \mathrm{p}<0.05 ; * *, p<0.01$; $* * *, \mathrm{p}<0.001$. 
Actin-binding and regulatory proteins have been proposed to represent attractive targets for the development of innovative anti-angiogenic therapies [22]. However, the role of the actin cytoskeleton in angiogenesis has not been completely elucidated. Basic cell biology studies are crucially needed to map the specific role played by each component of the actin cytoskeleton in order to find new ways to target angiogenesis in pathologies such as cancer and rheumatoid arthritis. Here, we investigated the cellular distribution and localization of the two cytoplasmic isoforms of actin, $\beta$ and $\gamma$, in vascular endothelial cells and performed the first functional analysis of $\gamma$-actin in these cells, revealing a key role for this protein in angiogenesis.

Co-immunofluorescence staining using newly developed antibodies directed against $\beta$ - and $\gamma$-actin revealed a strong colocalization of the two cytoplasmic actin isoforms in vascular endothelial cells, albeit some level of spatial preference. Our findings are in accordance with the preferential localization of $\beta$-actin in radial stress fibres and membrane ruffling and $\gamma$-actin in the cortical microfilament meshwork previously reported in epithelial cells, fibroblasts [7] and more recently in neuroblastoma cells [ 8]. The subcellular localization of $\beta$ - and $\gamma$-actin expression appears to be mediated by localization of their respective mRNA [5]. Furthermore, studies have shown that $\beta$-and $\gamma$-actin differentially interact with accessory proteins such as tropomyosins [23] and non-sarcomeric myosins [ 24]. These differential interactions may govern the specific functions of $\beta$ - and $\gamma$-actin, and therefore contribute to the spatial and temporal regulation of cytoskeletal dynamics.

Significant knockdown of $\beta$-actin could not be achieved in vascular endothelial cells without inducing major cytotoxicity, suggesting that these cells are particularly sensitive to changes in $\beta$-actin expression. In contrast, $\gamma$-actin expression could be successfully knocked down by $50-60 \%$ in endothelial cells, indicating an isoform-specific function for actin in endothelial cells. This difference in response to $\beta$ and $\gamma$-actin knockdown is consistent with recent studies showing that $\beta$-actin knockout mice are not viable [9] unlike $\gamma$-actin knockout mice, which despite suffering increased mortality and showing progressive hearing loss during adulthood, are viable [10].

Interestingly, $\gamma$-actin knockdown almost completely suppressed the capacity of endothelial cells to maintain capillary-like structures on Matrigel $^{\mathrm{TM}}$. Timelapse videomicroscopy analysis revealed that $\gamma$ actin was dispensable in the early steps of the morphological differentiation process (i.e. vascular sprouting) but required to sustain newly formed vascular networks. Previous studies have shown that the major endothelial cell adhesion molecule, VE-cadherin, plays a crucial role in angiogenesis - reviewed in [ 25- 27]. The development of a VE-cadherin knockout ( $C d h 5-/-$ ) mouse model thus revealed that this type II cadherin is dispensable in de novo blood vessel formation but essential to prevent the regression and ensure the maturation of nascent blood vessels [ 28, 29]. We therefore hypothesized that VE-cadherin may be involved in the vascular regression induced by $\gamma$-actin knockdown. Our results showed that the expression of VE-cadherin is rapidly up-regulated during the morphological differentiation of endothelial cells, which is consistent with the study by Prandini et al. demonstrating that VE-cadherin promoter activity is enhanced during angiogenesis [ 30]. Furthermore, we found that the up-regulation of VE-cadherin was impaired in $\gamma$-actin siRNA-treated cells, which may contribute to vascular regression in these cells. This finding is in agreement with a recent study showing that VEcadherin is involved in the cessation of endothelial cell sprouting [31]. Elsewhere, recent studies have shown that the major receptor involved in angiogenesis, VEGFR-2, may be in part regulated by the actin cytoskeleton. For instance, its localization to the plasma membrane has been shown to be mediated by myosin 1C, an unconventional motor protein trafficking along actin filaments [ 32]. In addition, inhibition of Rho GTPase Rac1 was found to down-regulate the expression VEGFR-2 [ 33]. However, we demonstrated herein that VEGFR-2 expression was up-regulated in endothelial cells during the angiogenic process independently of $\gamma$-actin expression.

To better understand how $\gamma$-actin knockdown impaired the angiogenic process, we investigated its impact on endothelial cell adhesion, chemotaxis and motility. While partially depleting $\gamma$-actin expression did not alter cell adhesion, it significantly reduced the capacity of endothelial cells to respond to chemotactic stimuli, randomly explore their microenvironment and colonize a new area. This result is in line with other studies demonstrating the crucial role played by the actin cyto skeleton in cell locomotion in non-endothelial cells - reviewed by Le Clainche and Carlier [ 34]. It is also consistent with the results recently reported for $\gamma$-actin depleted epithelial cells [ 7], arguing in favour of a crucial role of $\gamma$-actin in the control of directional motility in diverse cell types.

We previously reported that $\gamma$-actin regulates neuroblastoma cell migration by modulating ROCK signalling pathway [ 8]. Here, we extended this finding to vascular endothelial cells. Indeed, $\gamma$-actin 
knockdown was associated with accumulation of thicker actin stress fibres, larger focal adhesions and increased phosphorylation of myosin light chain 2 in endothelial cells, thus strongly suggesting activation of the ROCK signalling pathway. Furthermore, incubation with pharmacological inhibitors of ROCK signalling completely restored the motility of $\gamma$-actin siRNA-treated cells, demonstrating that the $\gamma$-actin knockdown motility phenotype is dependent upon ROCK activation. In contrast, ROCK inhibitors only partially rescued the angiogenic potential of $\gamma$-actin knockdown cells, suggesting that $\gamma$ actin regulates angiogenesis through both ROCK-dependent and ROCK-independent mechanisms.

Interestingly, VE-cadherin engagement has been shown to activate numerous biochemical pathways that can affect cell shape and adhesion, including the ROCK signalling pathway [ 35- 37]. Furthermore, a direct link was recently reported between actin stress fibres and the protein complex forming adherens junctions, VE-cadherin/ $\beta$-catenin/ $\alpha$-catenin [ 38, 39]. Here we provide evidence of the reverse relationship since decreasing the expression of $\gamma$-actin partially blocked the required up-regulation of VE-cadherin expression during morphological differentiation of endothelial cells. Additional experiments are currently underway to fully decipher the mechanisms involved in the crosstalk between $\gamma$-actin, ROCK signalling and VE-cadherin, which appears to play a critical role in the maintenance of newly formed vascular networks.

\section{Conclusions}

Collectively our results demonstrate for the first time that $\gamma$-actin plays a crucial role in angiogenesis through the regulation of endothelial cell motility and neovessel maintenance, via ROCK-dependent and -independent mechanisms. This finding opens potential therapeutic avenues for the treatment of angiogenesis-related disorders by targeting key factors involved in the $\gamma$-actin/VE-cadherin/ROCK signalling network.

\section{Abbreviations}

- ECM: Extra-cellular matrix

- FCS: Fetal calf serum

- FGF: Fibroblast growth factor $\beta$

- HMEC-1: Human microvascular endothelial cell line 1

- MLC2: Myosin light chain 2

- siRNA: Small interfering RNA

- ROCK: Rho-associated protein kinase

- VE-cadherin: Vascular endothelial cadherin

- VEGFR-2: Vascular endothelial growth factor receptor 2

\section{Declarations}

\section{Acknowledgments}

The authors would like to thank Dr Christine Chaponnier (University of Geneva, Switzerland) for generously providing the $\beta$ - and $\gamma$-actin monoclonal antibodies and Dr Karen MacKenzie (Children's Cancer Institute Australia) for providing the BMH29L endothelial cell line. This work was supported by the Children's Cancer Institute Australia for Medical Research, which is affiliated with the University of New South Wales and Sydney Children's Hospital, and by grants from the Cancer Institute New South Wales (EP) and Cancer Council New South Wales (MK). EP was supported by a Cancer Institute New South Wales "Early Career Development" Fellowship. MK is supported by a NHMRC Senior Research Fellowship (APP1058299) and an Australian Research Council Centre of Excellence in Convergent Bio-Nano Science and Technology.

\section{Additional files}

Additional file 1: Figure S1. 
Quantification of $\beta$ - and $\gamma$-actin colocalization. (A) Scatter dot plot showing the Pearson's coefficient of individual HMEC-1 cells treated for $72 \mathrm{~h}$ with control (o) or $\gamma$-actin siRNA ( $\Delta)$. Bars , mean of three individual experiments with SE. Statistics were calculated by comparing control siRNA-versus $\gamma$-actin siRNA-transfected cells. ${ }^{* * *}, p<0.001$. (B) Representative 2-Dimensional histograms (fluorograms) showing a single linear relationship in high correlating samples (left) and multiple linear relationships in lower correlating cells ( right). This shows that the lower correlation of $\beta$-actin and $\gamma$-actin signals in some cells was mostly due to variations in stoichiometry rather complete segregation of the two isoforms.

Additional file 2: Figure S2.

Effect of $\gamma$-actin knockdown on the actin cytoskeleton. Representative photographs of BMH29L endothelial cells treated for $72 \mathrm{~h}$ with control (left) or $\gamma$-actin siRNA ( right) and stained with $\beta$-actin (top) and $\gamma$-actin ( middle) antibodies. The merged photographs (bottom) show $\beta$-actin in green, $\gamma$-actin in red and DNA (DAPI) in blue. Scale bar , $20 \mu \mathrm{m}$.

Additional file 3: Figure S3.

Effect of $\gamma$-actin knockdown on the formation vascular networks on Matrigel ${ }^{T M}$ using a different siRNA sequence. (A) Representative immunoblots of HMEC-1 cell lysates following treatment with control and $\gamma$-actin siRNA2 for $72 \mathrm{~h}$. Membranes were probed with anti- $\beta$-actin, anti- $\gamma$-actin and anti-GAPDH (loading control) antibodies. (B) Histogram showing the relative protein expression of $\gamma$-actin as determined by densitometry after normalization with GAPDH (loading control), following treatment with control (white) and $\gamma$-actin siRNA2 (black) for 72 h. Columns, means of three individual experiments; bars, SE. Statistics were calculated by comparing $\gamma$-actin expression level in control and $\gamma$-actin siRNA2-treated HMEC-1 cells; ***, $p<0.001$. (C) Representative photographs of HMEC-1 cells incubated for $8 \mathrm{~h}$ on Matrigel $^{T M}$ and following treatment with either control (left) or $\gamma$-actin siRNA ( bottom ) for $72 \mathrm{~h}$. Scale bar , $250 \mu \mathrm{m}$. (D) Histogram showing the surface occupied by vascular networks following treatment with control (white) and $\gamma$-actin siRNA (black) for $72 \mathrm{~h}$. Columns, means of three individual experiments; bars , SE. Statistics were calculated by comparing the mean surface occupied by vascular networks per view field (at least 10 view fields per condition) for control and $\gamma$-actin siRNA-treated HMEC-1 cells. ***, $p<0.001$. Additional file 4:

Supplementary videos 1-2.Representative time-lapse videomicroscopy experiments of control siRNA-and $\gamma$-actin siRNA-treated endothelial cells on Matrigel ${ }^{T M}$. BMH29L cells were seeded on Matrigel ${ }^{T M} 72 \mathrm{~h}$ after transfection with either control (Video 1) or $\gamma$-actin siRNA (Video 2). Photographs were taken every 5 min for $12 \mathrm{~h}$, using the $5 \mathrm{X}$ objective of an Axiovert 200M fluorescent microscope coupled to an AxioCamMR3 camera driven by the AxioVision 4.7 software.

Additional file 5: Figure S4.

Effect of $\gamma$-actin knockdown on VE-cadherin and VEGFR-2 expression at steady state and during the angiogenic process. (A) Representative immunoblots of HMEC-1 ( left ) and BMH29L ( right) cell lysates following treatment with control and $\gamma$-actin siRNA for $72 \mathrm{~h}$. Membranes were probed with anti-VEGFR-2, anti-VE-cadherin, anti- $\gamma$-actin and anti- $\alpha$-tubulin (loading control) antibodies. (B) Representative immunoblots of HMEC-1 cell lysates obtained at different time points of the morphological differentiation process on Matrigel ${ }^{T M}$, following treatment with either control ( left ) or $\gamma$-actin siRNA (right) for 72 h. Membranes were probed with anti-VEGFR-2, anti- $\gamma$-actin and anti-GAPDH (loading control) antibodies.

Additional file 6: Figure S5.

Effect of $\gamma$-actin knockdown on the microtubule network. Representative photographs of HMEC-1 cells treated for $72 \mathrm{~h}$ with control (left) and $\gamma$-actin siRNA (right) and stained with anti-tubulin antibody. Scale bar , $20 \mu \mathrm{m}$.

Additional file 7: Figure S6.

Effect of ROCK signalling inhibition on $\gamma$-actin knockdown-induced motility inhibition. Representative photographs of wound healing experiments with control and $\gamma$-actin 
siRNA-transfected BMH29L cells. Endothelial cells were either untreated (left) or pretreated with H-1152 ( middle) or Y-27632 ( right) at $10 \mu \mathrm{M}$ for 24 hours and during the course of the experiment. Broken lines show the position of the initial cell-free gap (at time 0) and solid lines highlight the position of the migration edge after $8 \mathrm{~h}$. Inset, \% of wound closure.

Additional file 8: Figure S7.

Effect of ROCK signalling inhibition on $\gamma$-actin knockdown-induced vascular regression. (A)Representative photographs of BMH29L cells incubated for 8 h on Matrigel ${ }^{T M}$. Cells were transfected with either control (top) or $\gamma$-actin siRNA ( bottom) for $72 \mathrm{~h}$ and either untreated ( left ) or treated with $10 \mu M$ ROCK inhibitors, H-1152 ( middle ) or Y-27632 ( right ). Inset, \% of angiogenesis inhibition as compared to untreated control cells. Scale bar , $250 \mu \mathrm{m}$. (B) Histogram showing the surface occupied by vascular networks following treatment with control (white) and $\gamma$-actin siRNA ( black) for $72 \mathrm{~h}$. Columns, means of at least four individual experiments; bars, SE. Statistics were calculated by comparing the mean surface occupied by vascular networks per view field (at least 10 view fields per condition) for control siRNA-vs $\gamma$-actin siRNA-transfected cells unless indicated otherwise. *, $p<0.05$; ***, $p<0.001$.

\section{Competing interests}

The authors declare no conflict of interests.

\section{Authors' contributions}

EP and MK designed the study, EP, MPT and SS performed the experiments and analysed the data, MC and AM performed the colocalization analysis, EP wrote the manuscript, MK edited the manuscript. All authors read and approved the manuscript.

\section{References}

1. Carmeliet P. Angiogenesis in life, disease and medicine. Nature. 2005;438:932-936. View Article Google Scholar

2. Ferrara N, Kerbel RS. Angiogenesis as a therapeutic target. Nature. 2005;438:967-974. View Article Google Scholar

3. Pasquier E, Andre N, Braguer D. Targeting microtubules to inhibit angiogenesis and disrupt tumour vasculature: implications for cancer treatment. Curr Cancer Drug Targets. 2007;7:566-581.

View Article Google Scholar

4. Tondeleir D, Vandamme D, Vandekerckhove J, Ampe C, Lambrechts A. Actin isoform expression patterns during mammalian development and in pathology: insights from mouse models. Cell Motil Cytoskeleton. 2009;66:798-815.

View Article Google Scholar

5. Hill MA, Gunning P. Beta and gamma actin mRNAs are differentially located within myoblasts. J Cell Biol. 1993;122:825-832.

View Article Google Scholar

6. Bassell GJ, Zhang H, Byrd AL, Femino AM, Singer RH, Taneja KL, et al. Sorting of betaactin $m R N A$ and protein to neurites and growth cones in culture. $J$ Neurosci. 1998;18:251-265. 
7. Dugina V, Zwaenepoel I, Gabbiani G, Clement S, Chaponnier C. Beta and gammacytoplasmic actins display distinct distribution and functional diversity. J Cell Sci. 2009;122:2980-2988.

View Article Google Scholar

8. Shum MS, Pasquier E, Po'uha ST, O'Neill GM, Chaponnier C, Gunning PW, et al. gammaActin regulates cell migration and modulates the ROCK signaling pathway. FASEB J. $2011 ; 25: 4423-4233$.

View Article Google Scholar

9. Bunnell TM Burbach BJ Shimizu Y JM E $\beta$-Actin specifically controls cell growth, migration, and the G-actin pool Mol Biol Cell 20112240474058 10.1091/mbc.E11-06-05823204067

10. Belyantseva IA Perrin BJ Sonnemann KJ Zhu M Stepanyan R McGee J Gammaactin is required for cytoskeletal maintenance but not development Proc Natl Acad Sci U S A 200910697039708 10.1073/pnas.09002211062701000

11. Ades EW, Candal FJ, Swerlick RA, George VG, Summers S, Bosse DC, et al. HMEC-1: establishment of an immortalized human microvascular endothelial cell line. J Invest Dermatol. 1992;99:683-690.

View Article Google Scholar

12. MacKenzie KL, Franco S, Naiyer AJ, May C, Sadelain M, Rafii S, et al. Multiple stages of malignant transformation of human endothelial cells modelled by co-expression of telomerase reverse transcriptase, SV4O T antigen and oncogenic N-ras. Oncogene. 2002;21:4200-4211.

View Article Google Scholar

13. Verrills NM, Po'uha ST, Liu ML, Liaw TY, Larsen MR, Ivery MT, et al. Alterations in gamma-actin and tubulin-targeted drug resistance in childhood leukemia. J Natl Cancer Inst. 2006;98:1363-1374.

View Article Google Scholar

14. Harborth J, Elbashir SM, Bechert K, Tuschl T, Weber K. Identification of essential genes in cultured mammalian cells using small interfering RNAs. J Cell Sci. 2001;114:45574565.

View Article Google Scholar

15. Pasquier E Tuset MP Street J Sinnappan S MacKenzie KL Braguer D Concentration- and schedule-dependent effects of chemotherapy on the angiogenic potential and drug sensitivity of vascular endothelial cells Angiogenesis 201216 373386 10.1007/s10456-012-9321-x3595478

16. Winer J, Jung CK, Shackel I, Williams PM. Development and validation of real-time quantitative reverse transcriptase-polymerase chain reaction for monitoring gene expression in cardiac myocytes in vitro. Anal Biochem. 1999;270:41-49.

View Article Google Scholar

17. Schevzov G, Vrhovski B, Bryce NS, Elmir S, Qiu MR, O'Neill GM, et al. Tissue-specific tropomyosin isoform composition.J Histochem Cytochem. 2005;53:557-570.

View Article Google Scholar

18. Pasquier E, Sinnappan S, Munoz MA, Kavallaris M. ENMD-1198, a new analogue of 2methoxyestradiol, displays both antiangiogenic and vascular-disrupting properties. Mol Cancer Ther. 2010;9:1408-1418. 
19. Kouvroukoglou S, Dee KC, Bizios R, McIntire LV, Zygourakis K. Endothelial cell migration on surfaces modified with immobilized adhesive peptides. Biomaterials. 2000;21:1725-1733.

View Article Google Scholar

20. Valentiner U, Haane C, Nehmann N, Schumacher U. Effects of bortezomib on human neuroblastoma cells in vitro and in a metastatic xenograft model. Anticancer Res. 2009;29:1219-1225.

View Article Google Scholar

21. Adler J, Parmryd I. Quantifying colocalization by correlation: the Pearson correlation coefficient is superior to the Mander's overlap coefficient. Cytometry A. 2010;77:733-742.

View Article Google Scholar

22. Thoenes L, Gunther M. Novel approaches in anti-angiogenic treatment targeting endothelial F-actin: a new anti-angiogenic strategy? . Curr Opin Mol Ther. 2008;10:579-590.

View Article Google Scholar

23. Schevzov G, Lloyd C, Hailstones D, Gunning P. Differential regulation of tropomyosin isoform organization and gene expression in response to altered actin gene expression. J Cell Biol. 1993;121:811-821.

View Article Google Scholar

24. Müller M Diensthuber RP Chizhov I Claus P Heissler SM Preller M Distinct functional interactions between actin isoforms and nonsarcomeric myosins PLoS One 20138 e70636 10.1371/journal.pone.00706363724804

25. Cavallaro U, Liebner S, Dejana E. Endothelial cadherins and tumor angiogenesis. Exp Cell Res. 2006;312:659-667.

View Article Google Scholar

26. Lampugnani $M G$, Dejana E. Adherens junctions in endothelial cells regulate vessel maintenance and angiogenesis. Thromb Res. 2007;120:S1-S6.

View Article Google Scholar

27. Vestweber D. VE-cadherin: the major endothelial adhesion molecule controlling cellular junctions and blood vessel formation. Arterioscler Thromb Vasc Biol. 2008;28:223-232.

View Article Google Scholar

28. Carmeliet P, Lampugnani MG, Moons L, Breviario F, Compernolle V, Bono F, et al. Targeted deficiency or cytosolic truncation of the VE-cadherin gene in mice impairs VEGF-mediated endothelial survival and angiogenesis. Cell. 1999;98:147-157. View Article Google Scholar

29. Crosby CV, Fleming PA, Argraves WS, Corada M, Zanetta L, Dejana E, et al. VE-cadherin is not required for the formation of nascent blood vessels but acts to prevent their disassembly. Blood. 2005;105:2771-2776.

View Article Google Scholar

30. Prandini MH Dreher I Bouillot S Benkerri S Moll T Huber P The human VEcadherin promoter is subjected to organ-specific regulation and is activated in 
tumour angiogenesis Oncogene 20052429923001

10.1038/sj.onc.12084832800996

31. Abraham S, Yeo M, Montero-Balaguer M, Paterson H, Dejana E, Marshall CJ, et al. VEcadherin-mediated cell-cell interaction suppresses sprouting via signalling to MLC2 phosphorylation. Curr Biol. 2009;19:668-674.

View Article Google Scholar

32. Tiwari A Jung JJ Inamdar SM Nihalani D Choudhury A The myosin motor Myolc is required for VEGFR2 delivery to the cell surface and for angiogenic signalling Am J Physiol Heart Circ Physiol 2013304 H687 H696 10.1152/ajpheart.00744.20123602755

33. Meissner M, Michailidou D, Stein M, Hrgovic I, Kaufmann R, Gille J. Inhibition of Rac1 GTPase downregulates vascular endothelial growth factor receptor-2 expression by suppressing Spl-dependent DNA binding in human endothelial cells. Exp Dermatol. 2009; 18:863-869.

View Article Google Scholar

34. Le Clainche C, Carlier MF. Regulation of actin assembly associated with protrusion and adhesion in cell migration. Physiol Rev. 2008;88:489-513.

View Article Google Scholar

35. Lampugnani MG Zanetti A Breviario F Balconi G Orsenigo F Corada M VEcadherin regulates endothelial actin activating Rac and increasing membrane association of Tiam Mol Biol Cell 20021311751189 10.1091/mbc.01-070368102260

36. Kouklis $P$, Konstantoulaki M, Malik AB. VE-cadherin-induced Cdc42 signaling regulates formation of membrane protrusions in endothelial cells. J Biol Chem. 2003;278:16230-16236.

View Article Google Scholar

37. Nelson CM Pirone DM Tan JL Chen CS Vascular endothelial-cadherin regulates cytoskeletal tension, cell spreading, and focal adhesions by stimulating RhoA Mol Biol Cell 20041529432953 10.1091/mbc.E03-10-0745420116

38. Millan J Cain RJ Reglero-Real N Bigarella C Marcos-Ramiro B Fernández-Martín $L$ Adherens junctions connect stress fibres between adjacent endothelial cells BMC Biol 2010811 10.1186/1741-7007-8-112845098

39. Noda K Zhang J Fukuhara S Kunimoto S Yoshimura M Mochizuki N Vascular endothelial-cadherin stabilizes at cell-cell junctions by anchoring to circumferential actin bundles through alpha- and beta-catenins in cyclic AMP-Epac-Rap1 signalactivated endothelial cells Mol Biol Cell 201021584596 10.1091/mbc.E09-0705802820423 